Innovative Technology Advocate - Formerly Used Defense Sites

\title{
Chemical Degradation of PCBs in Alaskan Soils
}

Scott A. Waisner, Agnes B. Morrow, Catherine C. Nestler, April 2011

Charles Coyle, and Victor F. Medina 


\title{
Chemical Degradation of PCBs in Alaskan Soils
}

\author{
Scott Waisner, Agnes B. Morrow, Victor F. Medina \\ U.S. Army Engineer Research and Development Center \\ Environmental Laboratory \\ 3909 Halls Ferry Road \\ Vicksburg, MS 39180-6199 \\ Charles G. Coyle \\ U.S. Army Corps of Engineers \\ Environmental and Munitions Center of Expertise \\ 1616 Capitol Ave., Suite 9200 \\ Omaha, NE 68102-9200 \\ Catherine C. Nestler \\ Applied Research Associates, Inc., Southern Division \\ 119 Monument Place \\ Vicksburg, MS 39180
}

Final report

Approved for public release; distribution is unlimited.

\author{
Prepared for U.S. Army Corps of Engineers \\ Washington, DC 20314-1000 \\ Under Work Unit 33143
}




\begin{abstract}
Previous work suggested that the addition of lime could promote the removal of polychlorinated biphenyls (PCBs), presumably by alkaline hydrolysis reactions. A study was conducted to determine if a modified process (substituting sodium hydroxide $(\mathrm{NaOH})$ for lime) could be used to treat PCB-contaminated soils in remote areas of Alaska. Experiments in which soils were reacted with $2 \% \mathrm{NaOH}$ and a $\mathrm{NaOH} /$ zero valent iron mixture resulted in an approximate 20 to $30 \%$ reduction of Aroclor concentration compared to the controls. Tests applying Tween 80 at $15 \%$ $(\mathrm{w} / \mathrm{w})$ with $\mathrm{NaOH}$ at $2 \%(\mathrm{w} / \mathrm{w})$ indicated that the Tween 80 increased PCB release from soil, but no significant PCB degradation was found. An experiment was then conducted to investigate the use of persulfate to treat PCBs in solution. Heat-activated $\left(50^{\circ} \mathrm{C}\right)$ sodium persulfate $\left(\mathrm{Na}_{2} \mathrm{~S}_{2} \mathrm{O}_{8}\right)$ removed $>90 \%$ of the PCBs (Aroclor 1254), but lime-activated persulfate was ineffective. A final study was conducted to investigate the effect of hydroxide and lime on PCB extraction and the effect of $\mathrm{pH}$ neutralization. The study was inconclusive, as it did not appear any net losses were demonstrated. The overall study indicated that alkaline hydrolysis does not appear to be effective for the treatment of the subject Alaska soils. Some promise might be found for heat-activated persulfate treatment, although the more easily applied lime activation was not effective.
\end{abstract}

DISCLAIMER: The contents of this report are not to be used for advertising, publication, or promotional purposes. Citation of trade names does not constitute an official endorsement or approval of the use of such commercial products. All product names and trademarks cited are the property of their respective owners. The findings of this report are not to be construed as an official Department of the Army position unless so designated by other authorized documents. 


\section{Contents}

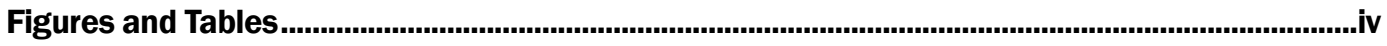

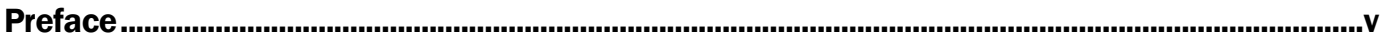

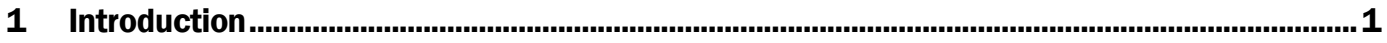

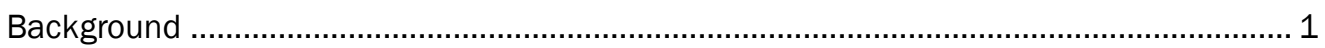

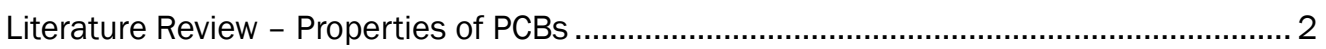

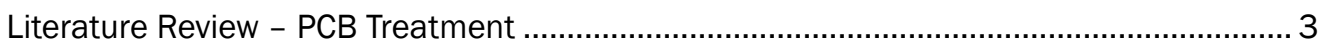

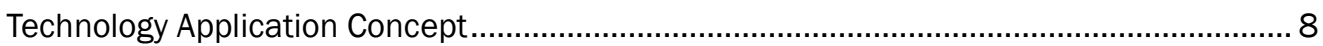

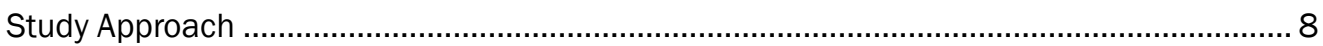

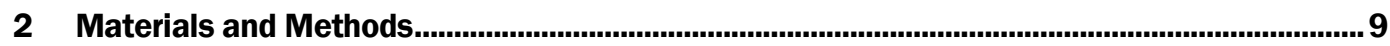

Soil

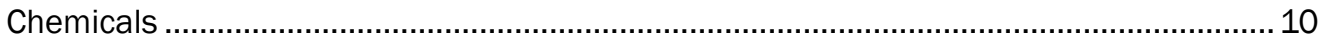

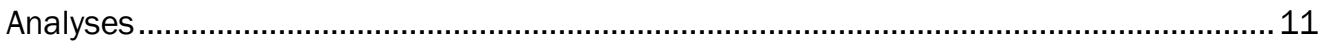

Alkaline Demand of Soil and Amendment Interactions ................................................. 11

Alkaline and Alkaline with ZVI Treatability Test.............................................................. 12

Surfactant Addition to Alkaline and Alkaline with ZVI Treatability Test .............................13

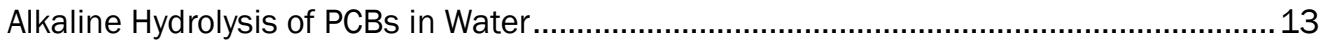

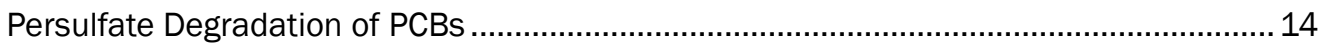

Effect of High Alkalinity on PCB Extractions................................................................. 14

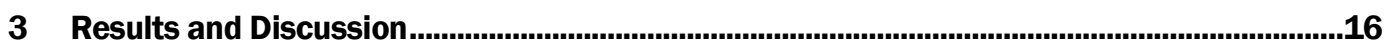

Alkaline Demand of Soil and Amendment Interactions ................................................... 16

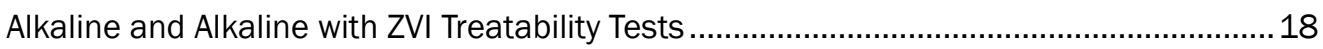

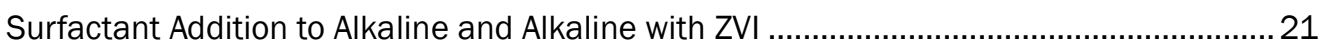

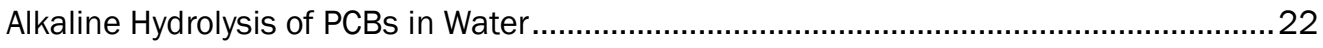

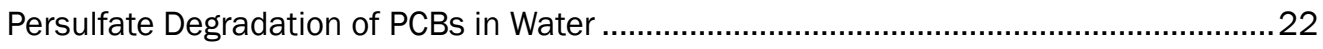

Effect of High Alkalinity on PCB Extractions.............................................................. 24

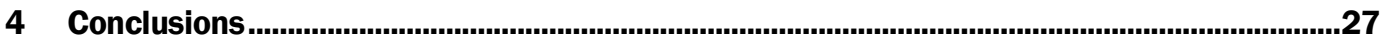

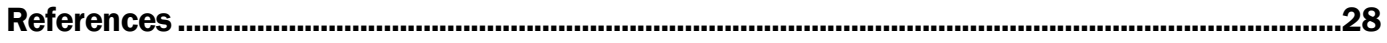

Appendix A: Cost Comparison of PCB-contaminated Soil Disposal at a Hazardous

Waste Landfill Versus On-site Treatment, Assuming a Remote Alaskan Site.

(Prepared with assistance from Neil Folcik, Ron Broyles, \& Scott Kendall of

Alaska District) ................................................................................................................31

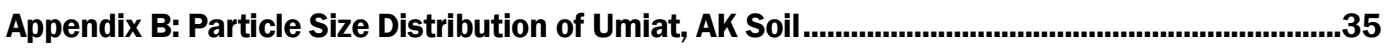

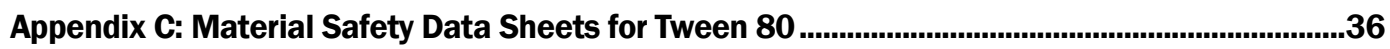

\section{Report Documentation Page}




\section{Figures and Tables}

\section{Figures}

Figure 1. The generalized chemical structure of polychlorinated biphenyl (PCB) compounds.

Figure 2. Reaction of PCB with nucleophile (top) and an alkoxide (bottom), after Hutzinger

et al. (1974).

Figure 3. Alkaline hydrolysis of PCB with a co-solvent (after Brunelle et al. 1985)............................. 4

Figure 4. Photo of test soil collection site. .......................................................................................

Figure 5. ZVI before and after Pulvisette...................................................................................

Figure 6. Dry soil with amendments before and after mixing..........................................................12

Figure 7. Treated slurry before and after centrifugation. ...........................................................13

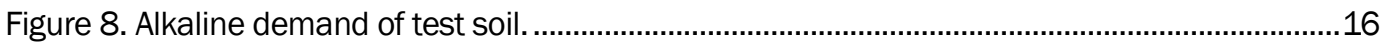

Figure 9. Estimate of Tween $80 \mathrm{CMC}$ with soil.................................................................................17

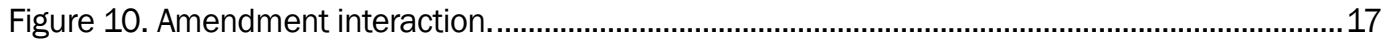

Figure 11. Effect of air-drying on control samples.........................................................................18

Figure 12. Total PCB results for alkaline and alkaline with ZVI tests..............................................19

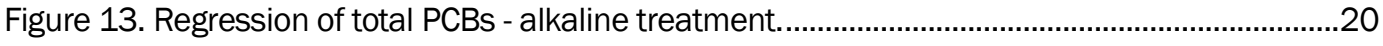

Figure 14. Regression of total PCBs - alkaline with ZVI treatment..................................................20

Figure 15. Total PCBs of Tween 80 addition to Alkaline and Alkaline plus ZVI Treatment................22

Figure 16. Alkaline hydrolysis of PCBs in aqueous solution............................................................23

Figure 17. PCB results of persulfate tests....................................................................................23

Figure 18. Degradation of PCBs by heat-activated $\left(50^{\circ} \mathrm{C}\right)$ persulfate...............................................2

Figure 19. PCB results for alkaline-activated persulfate..................................................................25

Figure 20. Activation of persulfate by alkaline $(\mathrm{pH}=12.5)$ conditions............................................2

Figure 21. PCB results of alkalinity effect on extraction. ...............................................................26

\section{Tables}

Table 1. Relevant physical and chemical data on the PCB Aroclor 1260 (ATSDR 2000)....................

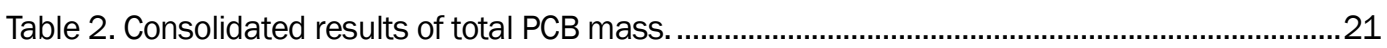




\section{Preface}

This report stems from experimental work conducted under funding provided by the USACE Formerly Used Defense Sites program via a Military Interdepartmental Purchase Request (MIPR). The study was coordinated with the Environmental and Munitions Center of Expertise (EM CX), and the USACE Innovative Technology Advocate Program. Chuck Coyle, P.E., of the EM CX assisted with: obtaining funding for the study; cost estimating for field implementation of the treatment process concept; coordination between ERDC and Alaska District; and monitoring the progress of the project. The purpose was to investigate chemical treatment as a means for treating PCB contaminated soils from remote locations in Alaska. This research effort was directed by Scott Waisner, P.E., under the oversight Victor F. Medina, Ph.D., P.E., team leader of the Environmental Security Engineering Branch. Agnes Morrow and Michael J ones provided laboratory support.

This report was prepared by Scott Waisner, Agnes Morrow and Dr. Victor Medina, all of the Environmental Engineering Branch, Environmental Processes and Engineering Division, U.S. Army Corps of Engineers Environmental Laboratory (EL). Catherine Nestler, Applied Research Associates, Inc., prepared some literature research sections. Chris Griggs and Dennis Brandon provided in-house review.

This study was conducted under the direct supervision of William Andrew Martin, Chief, Environmental Engineer Branch, and under the general supervision of Dr. Warren Lorentz, Chief, Environmental Process and Engineering Division, (EPED), and Dr. Elizabeth C. Fleming, Director, EL.

At the time of publication of this report, COL Kevin J. Wilson was Commander and Executive Director of ERDC, and Dr. J effery Holland, was Director. 


\section{Introduction}

These are the results from a study conducted to investigate alkaline hydrolysis as a treatment process for PCB-contaminated soils found in Alaska. In a previous study, Alkaline hydrolysis was found to be effective at removing PCBs from soils at a former munitions productions facility (Waisner et al. 2008). The current project was funded by the Formerly Used Defense Sites (FUDS) program.

\section{Background}

There are over 35 properties currently under the management of the Alaska District's FUDS Program; these properties have been identified as having PCB-contaminated soils. Many of these sites are very remote, increasing the costs associated with soil removal. This same problem was encountered by the Hawaii District (i.e., small volumes of PCB-contaminated soils at remote island sites). A previous study conducted by ERDC involving the treatment of a PCB-contaminated soil yielded promising results (Medina et al. 2007; Waisner et al. 2008). One of the remediation technologies used was alkaline hydrolysis, in which contaminant degradation is initiated by high $\mathrm{pH}$ conditions resulting from the addition of hydrated lime $\left(\mathrm{Ca}(\mathrm{OH})_{2}\right)$. In one case, the PCB concentration was reduced from $23 \mathrm{mg} / \mathrm{kg}$ to just under $7 \mathrm{mg} / \mathrm{kg}$. Removal percentages ranged from 44 to $70 \%$. The majority of removal occurred in 24 hours. Other chemical treatments (persulfate, lime activated persulfate and Fenton's reagent) were also tested, and each significantly removed PCBs. However, the lime treatment was at least as effective in comparison, simpler to apply, and less expensive as well.

Other studies have also found PCB removal under alkaline treatment effective (Brunelle and Singleton 1985, Brunelle et al. 1985, Weber et al. 2002, Seok et al. 2005, Payne et al. 1991, Soundararajan 1991). Some of these studies involved elevated temperatures (Weber et al. 2002, Seok et al. 2005); however, there are others that describe alkaline-hydrolysis reactions under ambient conditions and document PCB transformation products (Payne et al. 1991, Soundararajan 1991). Einhaus et al. (1991) disputed the effectiveness of lime treatment for PCBs, attributing removal primarily to thermal desorption (volatilization), but analysis of the experimental conditions used in Medina et al. (2007) rules out removal strictly by desorption. Recent research performed by TetraTech modified 
the approach by using sodium hydroxide $(\mathrm{NaOH})$ instead of hydrated lime for treatment of 2,4,6-trinitrotoluene (TNT) and various isomers of ditrnitrotoluene (DNT); the claim was that the higher $\mathrm{pH}$ produced by $\mathrm{NaOH}$ results in faster degradation. It is purportedly more effective for the treatment of DNT (Britto et al. 2010) as well. The higher $\mathrm{pH}$ produced by $\mathrm{NaOH}$ was used to increase the rate of contaminant degradation. The TetraTech research also indicated that combining base-hydrolysis reactions with zero-valent iron can have a synergistic treatment effect.

The allowable treatment level for on-site disposal is the EPA Region 9 Preliminary Remediation Goal (PRG) of $1 \mathrm{mg} \mathrm{kg}^{1}$. If this can be achieved, then a recent cost estimate prepared by the EM CX and Alaska District suggests that an approximate $\$ 23,000$ decrease in costs could be realized for on-site treatment compared to disposal at a hazardous waste facility (Appendix A). If this were applicable to just ten sites, a savings of $\$ 230,000$ could be realized.

Several PCB treatments have been tried at different sites in the past. Although some PCB removal is almost always accomplished, the treatment usually does not end up meeting remediation goals. One hypothesis is that PCB removal is governed by desorption of the contaminant from the soil into the solution phase, where reaction with treatment amendments can readily take place.

\section{Literature Review - Properties of PCBs}

A generalized PCB structure is shown in Figure 1. Physical and chemical data for Aroclor 1260 are provided in Table 1. An important physical property of all the PCBs is their inertness; they resist both acid and alkaline degradation, and are thermally stable (Hutzinger et al. 1974). The PCBs are relatively insoluble in water and their solubility decreases with increasing chlorination. PCBs have a high potential for bioaccumulation, but do not appear to be toxic to plants. Positive carcinogenicity studies in rats have resulted in PCB classification in general as B2, probable human carcinogens (ATSDR 2000). A significant health impact is also derived from the byproducts of PCB combustion. These by-products include hydrogen chloride, and the highly toxic polychlorinated dibenzodioxins (PCDDs) and polychlorinated dibenzofurans (PCDFs). Four samples of site soil contaminated with PCB-Aroclor 1260, analyzed for combustion byproducts, resulted in total PCDF concentrations that ranged from 0.8 to $5.6 \mu \mathrm{g} / \mathrm{g}$. 


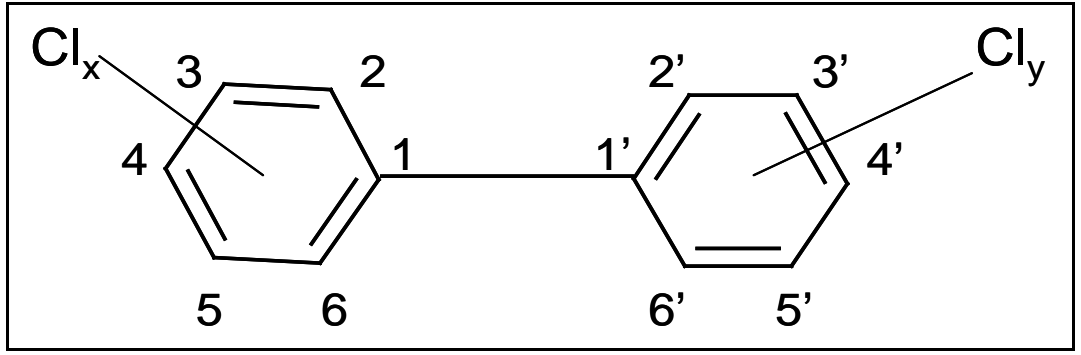

Figure 1. The generalized chemical structure of polychlorinated biphenyl (PCB) compounds.

Table 1. Relevant physical and chemical data on the PCB Aroclor 1260 (ATSDR 2000).

\begin{tabular}{|l|l|l|l|}
\hline Molecular weight & 358 & Partition coefficient: log Kow & 6.8 \\
\hline Color & Light yellow & $\begin{array}{l}\text { Vapor pressure, mm Hg @ } 25 \\
{ }^{\circ} \mathrm{C}\end{array}$ & $4.05 \times 10-5$ \\
\hline Physical state & Sticky resin & Solubility in water (mg/L) & $0.08 @ 24{ }^{\circ} \mathrm{C}$ \\
\hline Boiling point $\left({ }^{\circ} \mathrm{C}\right)$ & $385-420$ & Solubility in organic solvent & Very soluble \\
\hline $\begin{array}{l}\text { Density @ } 25{ }^{\circ} \mathrm{C} \\
\text { (g/cm3) }\end{array}$ & 1.62 & Chlorine content & $60 \%$ by weight \\
\hline
\end{tabular}

\section{Literature Review - PCB Treatment}

The treatment of PCBs by alkaline hydrolysis is a controversial topic.

While there are many articles that describe reactions and successful PCB degradation, other articles suggest that transformation is limited and removals are due to PCB volatilization. Furthermore, data obtained during the study described in this report (see Results and Discussion section), highlight the importance of verifying that proper sample processing procedures have been adhered to when assessing the efficacy of treatment processes for PCB-contaminated soil. Data taken from historical studies with unverifiable sampling procedures should be regarded with great caution.

Hutzinger et al. (1974) outlined the reaction of PCBs with alkoxides, a nucleophilic displacement of the chlorine atoms (Figure 2). Due to their general chemical inertness, many of the $\mathrm{PCB}$ reactions require the addition of a great deal of thermal energy. Manchak (1978) and Thyagarajan (1983) entered patent applications on cleaning transformer oils that involved the destruction of PCBs by alkaline hydrolysis at ambient temperatures. Thyagarajan (1983) treated PCB liquids with either potassium or sodium hydroxide $(\mathrm{KOH}$ or $\mathrm{NaOH})$ and then filtered the solution through diatomaceous earth or activated alumina. The PCB reacts with the hydroxyl ion to form a hydroxylated biphenyl that is absorbed during the filtering process. 


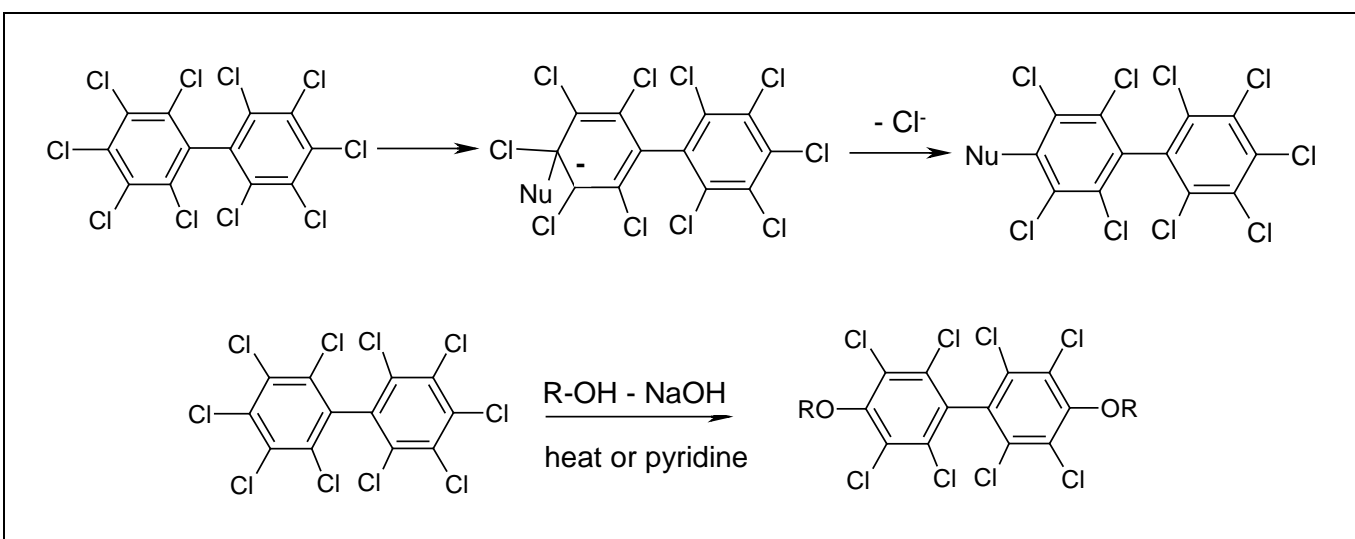

Figure 2. Reaction of PCB with nucleophile (top) and an alkoxide (bottom), after Hutzinger et al. (1974).

Brunelle and Singleton (1985) and Brunelle et al. (1985) reported on alkaline hydrolysis of PCBs in soil that also employed a co-solvent, polyethylene glycol (PEG). This reaction used a 3:1 (w/w) concentration of $\mathrm{KOH} / \mathrm{PEG}$ (Figure 3). An initial nucleophilic aromatic substitution reaction resulted in the methoxylation of the PCB at two of the chlorine sites. The methoxylated $\mathrm{PCB}$ continued to react with the excess $\mathrm{KOH}$, resulting in ring cleavage and the production of a polyglycol. The reaction proceeded slowly unless heat was added. It also required that the soil or sediment be dried before treatment. The authors compared PCB congeners with different chlorination concentrations and reported that the treatment works best on compounds with higher chlorine levels; i.e., the treatment worked better with Aroclor 1260 than with Aroclor 1254. They did not report any toxicity testing of the final product and glycol phenols have the potential, due to their high water solubility, for migration into groundwater.

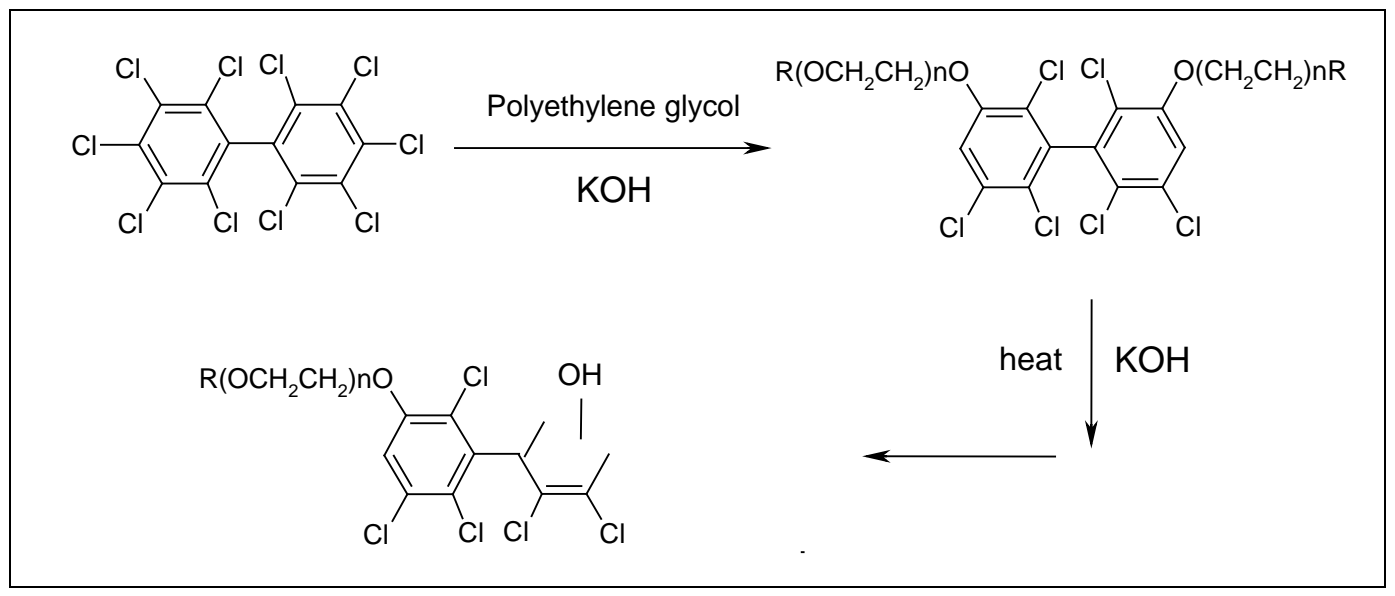

Figure 3. Alkaline hydrolysis of PCB with a co-solvent (after Brunelle et al. 1985). 
Payne et al. (1991) reported the complete dehalogenation of PCBs in soil at ambient temperature. They used quicklime, $\mathrm{CaO}$, that they "hydrophobized" by treatment with fatty acid, creating a granular substrate easily mixed into the soil/sediment/ sludge. The fatty acid absorbed and immobilized the PCB and then delayed and slowed the exothermic hydration reaction that produced the calcium hydroxide. The calcium hydroxide, which is in close proximity to the PCB molecule, initiated the dehalogenation reactions. Laboratory experiments on contaminated soils at ambient temperatures indicated a reaction time of several months, depending on the PCB concentration. Increasing the temperature of the reaction increased the destruction rate, bringing it down to several minutes at $400^{\circ} \mathrm{C}$. The released chloride forms calcium chloride $\left(\mathrm{CaCl}_{2}\right)$. No toxic chlorinated phenols were produced from this reaction.

Taniguchi et al. (2003) achieved a 99.79\% removal of PCB from soil using the Base Catalyzed Decomposition process at a temperature of $200{ }^{\circ} \mathrm{C}$. During this process $\mathrm{NaHCO}_{3}$ was augmented into the soil, and the organic matter in the soil served as a hydrogen donor.

Sedlak et al. (1991) studied the alkaline hydrolysis of PCBs using quicklime and attempted to discriminate between losses due to degradation and those due to volatilization/temperature effects. They concluded that the temperature of the reaction caused changes in the PCB partitioning between soil-airwater and that no abiotic degradation occurred. In contrast, Weber et al. (2002) and Seok et al. (2005) also examined the alkaline hydrolysis of PCB using flyash and quicklime, respectively, and both reported abiotic degradation. However, both of these efforts required the addition of heat to the reaction $\left(340^{\circ} \mathrm{C}\right.$ and $600^{\circ} \mathrm{C}$, respectively) as well as a non-oxygen atmosphere.

The United States Environmental Protection Agency (USEPA) prepared two reports reviewing treatment technologies -- including alkaline hydrolysis -for PCB-contaminated soil, sediments, sludge and water (Einhaus et al. 1991, Dàvila et al. 1993). In addition, a supplement to the Einhaus report, prepared by Soundararajan (1991), addresses the alkaline hydrolysis of PCBs exclusively. Einhaus et al. (1991) treated three different PCB congeners with quicklime in a closed reaction vessel and recorded a 60 to $80 \%$ decrease in PCB concentration after five hours. The authors concluded that this decrease was due to evaporation and steam stripping from the exothermic reaction, although they found some reaction products. Einhaus' 
results are contradicted by those of Soundararajan (1991), who attempted to replicate actual site conditions. Soundararajan found no volatilization of the PCBs, inorganic chloride was present in the final reaction mixture, and the biphenyl ring structure was destroyed. Dàvila et al. (1993) evaluated alternative technologies for treatment of PCB-contaminated soil and sediment. They divided the treatments into categories: established, demonstrated and emerging technologies. The use of quicklime (as cement kiln dust) was dismissed as a failed technology.

Waisner et al. (2008) revived interest in lime treatment by finding about 80\% removal of PCBs from soils collected from the former Plum Brook Ordnance Works. The study also investigated both heat and lime activated persulfate treatment. Lime treatment was comparable to the effectiveness of the persulfate treatment (also see Medina et al. 2007).

Cassidy (2010) attributed PCB losses found in previous studies as interferences with the extraction procedure, an effect he termed "lime lock." However, Cassidy determined that persulfate could be an effective treatment approach for PCB contaminated soils.

Zero valent iron has been investigated as a possible treatment of PCBs. Varanasi et al. (2007) studied the use of nano-iron to treat a PCBcontaminated soil. Unfortunately, few details are given about the PCB contaminations, such as aging information or the aroclor type. However, since the soil was already being treated by low temperature thermal desorption, it is likely that the PCBs were a relatively low chlorinated form. About 38\% reduction of PCB concentration was found by mixing the nanoparticles with soil/ water slurry at room temperature. The slurry was then heated, resulting in a minimum destruction efficiency of $95 \%$.

Other approaches have shown promise, and many of these have focused on increasing the desorption of PCBs from the soil matrix. Pressure-assisted ozonation was found to completely remove PCBs $(5.1 \mathrm{mg} / \mathrm{kg})$ from harbor sediments in $0.5 \mathrm{hrs}$ (Andy Hong et al. 2008). In this work, successive cycles of pressurization of $690 \mathrm{kPa}$ and depressurization exposed the contaminants to treatment by soil aggregate fracturing. Ehsan et al. (2007) achieved a 76\% removal of PCB using an ultra-sonication washing procedure with cyclodextrin and EDTA. Svab et al. (2009) were able to decrease the PCB concentration in a sandy soil from $34.3 \mathrm{mg} / \mathrm{kg}$ to less than $10 \mathrm{mg} / \mathrm{kg}$ by flushing the soil with an aqueous solution of Spolapon AOS 
146, an anionic surfactant. However, some synthetic surfactants can also be long-lasting and may lead to additional environmental pollution problems if used for in-situ remediation. Robinson et al. (1996) proposed the use of Rhamnolipid R1, a biosurfactant. This surfactant elevated PCB mineralization but only at levels above the critical micelle concentration.

An anaerobic thermal processor referred to as SoilTech ATP (EPA 1992) was found to reduce PCB concentrations in a contaminated feed soil from a Superfund site from $28.2 \mathrm{ppm}$ to $0.043 \mathrm{ppm}$. This process sprays the contaminated soils with diesel fuel and oil mixture containing alkaline polyethylene glycol reagents, heats the soils, and then treats the off gases by vacuum to recover the contaminants. However, it was not clear from the report if removal was due to degradation or due to thermal desorption/ degradation. It was also unclear whether samples were neutralized or dried before analysis.

A process marketed by Sonic Environmental Services reportedly uses high frequency sonication to desorb and destroy PCBs (McElroy 2005). One concern with the process is that it would result in the generation of hydrogen gas when elemental sodium is added to the soil-water slurry; this may be an explosion hazard. (There was no description of any kind of vapor control during treatment.) Another important unknown is the transportability of the treatment system equipment. The units are reportedly modular and transportable; however, the exact size andweight of the units -- andthe total system -- were not provided. Based on the photographs included in the paper, it appears the size of each modular unit might be on the order of $15 \times 15 \times 15$ feet.

Reactions based on Fenton's Reagent (a combination of hydrogen peroxide and reduced iron) have also been investigated for treatment of PCBs. Osgerby et al. (2002) investigated the use of Fenton's Reagent to treat PCB-contaminated sludge derived from thermal desorption of the contaminated coral soils on the island of Saipan. The method, which was developed using laboratory studies, used hydrogen peroxide (15\% dose strength) with sufficient caustic to reach a $\mathrm{pH}$ of 13/14. The process was one of chemical reduction wherein the peroxide generated hydroperoxide radicals, which are a strong nucleophyllic reductant. Various treatments based on this approach reduced PCB concentrations from 35 to nearly $98 \%$. However, the treatments were not able to meet the $1 \mathrm{mg} \mathrm{kg}^{-1}$ 
treatment goal. Based on discussions with Dr. Rick Watts, the soils were not neutralized or dried prior to analysis for PCBs.

Medina et al. (2007) also investigated a Fenton's Reagent reaction to treat soils found at the Former Plum Brook Ordnance Works. PCB reduction on the order of $70 \%$ was achieved with a reaction time of only about 15 minutes. The samples, however, were not neutralized, nor were they airdried.

\section{Technology Application Concept}

We have developed a conceptual model of actual application procedures as a guide for our experimental design. We envision that a team will take the chemical amendments to the site. The soil of concern would be excavated and processed if necessary, such as removal of rocks by the use of vibratory screening. Contaminated rocks will be cleaned by steam treatment. The soil will then be placed in a treatment area (a drum, a plastic containment vessel, metal roll-off bin, or HDPE plastic), and the additives will be mixed in based on a formula using a pug mill, a rototiller, or a drum roller. For very small volumes, rakes or other hand mixing equipment could be used. Samples will be taken as needed. We anticipate the treatment will require about four days at the site. Appropriate health and safety preparations (contact and inhalation protection) would be necessary.

\section{Study Approach}

The approach was to use small-scale reactors to investigate chemical treatment of PCB- contaminated soils collected from Alaska. The study focused on base hydrolysis by creating a high $\mathrm{pH}$ through the addition of sodium hydroxide and the treatment of PCBs by persulfate treatment, an advanced oxidation technology. Since we assumed that mass transfer from the soil to liquid phase would be the limiting condition for treatment, we also tested the addition of a surfactant to enhance treatment. 


\section{Materials and Methods}

Soil

The soil came from Umiat, Alaska, which is located on the North Slope of Alaska about 100 miles southwest of Prudhoe Bay. The specific site within the Umiat area was Test Well 9, an oil exploration well. Figure 4 is a picture of Test Well 9 and the area from which the soil was collected. The PCBs were used as a tracer in the drilling mud. Once the well was drilled and abandoned, the site was leveled around the well head and the soil was replaced with drilling mud all around the site. The soil was collected from an area between the surface and six feet belowground.

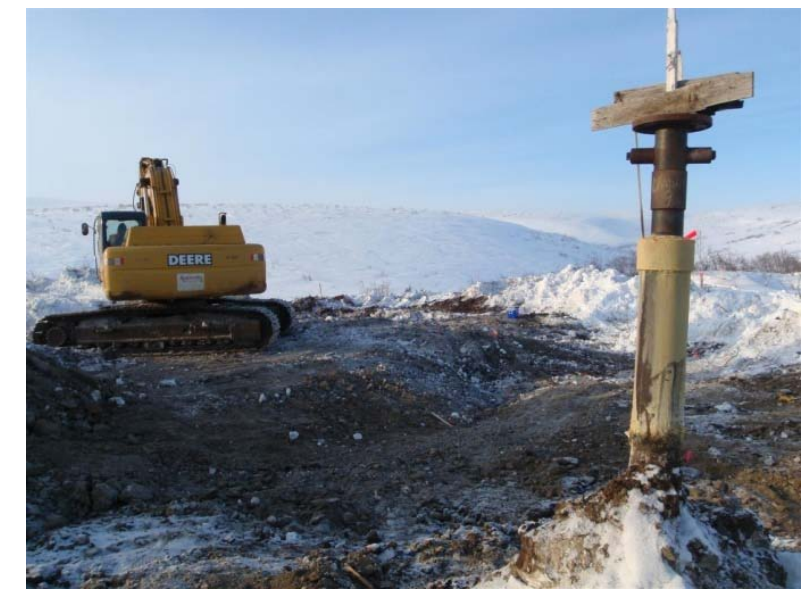

Figure 4. Photo of test soil collection site.

The soil was removed as part of a cleanup project and sent to Anchorage, Alaska, for transport to the continental United States. The drums were sub-sampled by Ronald Broyles of the Alaska District for use in the experiments. The soil was received at ERDC-Vicksburg in a 30-gallon open-top steel drum, which was about one-third full. The soil was air dried in the laboratory in shallow pans. Clods of dirt were broken down by hand, and large sticks and rocks were removed. The soil was then passed through a \#10 sieve, and the soil clods retained on the sieve were passed through a hammer-mill crusher (Holmes Bros., Inc. 201XL) to break them down further. The soil was then recombined in the original 30-gallon drum, which was placed on a drum roller for 24 hours to homogenize the soil. 
Five discreet samples of the homogenized soil were collected for PCB analysis from different depths and areas of the drum. The analysis indicated that it contained Aroclor 1254. The mean concentration of Aroclor 1254 was found to be $66,400 \mu \mathrm{g} / \mathrm{kg}$ with a standard deviation of 6,572 , which gives a coefficient of variation of $9.9 \%$. Particle size distribution of the soil is provided in Appendix B.

\section{Chemicals}

Deionized (DI) water was used in all procedures of the test. The water had a resistivity of approximately 18 mega ohm and was produced by a Barnstead NANOpure Infinity. Alkaline conditions in slurries were established with solutions made from sodium hydroxide $(\mathrm{NaOH})$ pellets purchased from Fisher Scientific (cat. \# S318-1, certified ACS, > 99.8\% NaOH) and DI water.

Zero-valent iron (ZVI) used in the test were produced from iron filings purchased from Fisher Scientific (cat. \# 157-500). The iron filings have an approximate mesh size of 40 . The particle size of the filings was reduced further by placing them in a planetary mill with bowls and balls made of agate (Pulverisette 5, Fritsch $\mathrm{GmbH}$ ). Figure 5 shows the iron filings before and after milling.
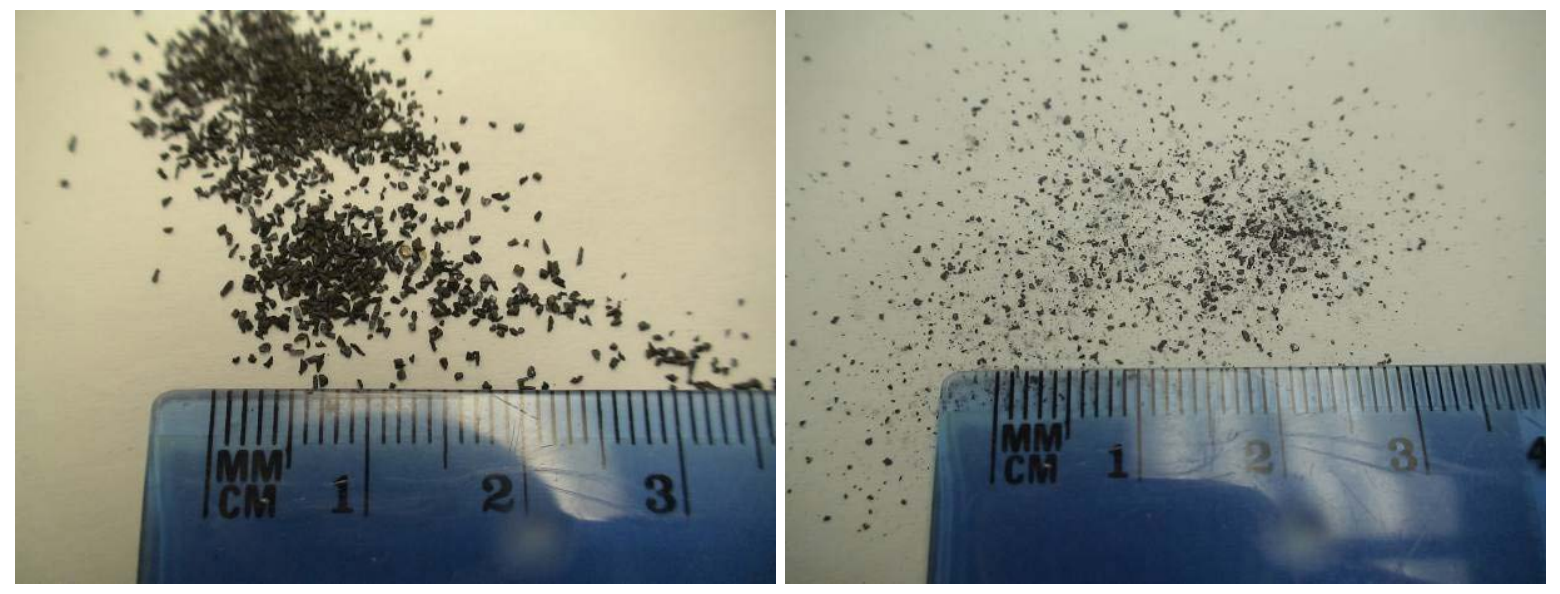

Figure 5. ZVI before and after Pulvisette.

Several additional chemicals were used to create the conditions in these tests. Hydrated lime, $\mathrm{Ca}(\mathrm{OH}) 2$, was a powder from an unknown commercial source. Sodium persulfate, $\mathrm{Na}_{2} \mathrm{~S}_{2} \mathrm{O}_{8}$, was a powder from Sigma Aldrich (216232) with a purity assay of $99.1 \%$. The nonionic surfactant Tween 80 (CAS 9005-65-6) was obtained from Sigma Aldrich (SIGMA P-1754) (See Appendix C for Material Safety Data Sheets). 
The source of the PCBs used for aqueous tests was a 1000- $\mu \mathrm{g} / \mathrm{mL}$ Aroclor 1254 standard in methanol obtained from Supelco. $1 \mathrm{~mL}$ of this standard was added to $20 \mathrm{~mL}$ of methanol to create a stock solution of $50-\mu \mathrm{g} / \mathrm{mL}$ Aroclor 1254 to be used in the tests.

\section{Analyses}

PCBs were extracted from the soil and water samples by EPA methods 3545 and 3510c, respectively. Hydromatrix was mixed with soil samples prior to extraction to absorb the water in the soil and maintain the permeability of the soil during the extraction process. The extracts were analyzed for PCBs according to EPA method 8082. The $\mathrm{pH}$ of water and soil slurries was determined with a pH electrode.

When the air-drying of soil was performed prior to extraction, this process took place in a laboratory oven at an ambient temperature of $25^{\circ} \mathrm{C}$. The actual oven temperature may have ranged from 22 to $28^{\circ} \mathrm{C}$.

\section{Alkaline Demand of Soil and Amendment Interactions}

A test was conducted to estimate the amount of $\mathrm{NaOH}$ addition necessary to maintain a $\mathrm{pH}$ of approximately 12.5 in soil-water slurry of the test soil. The test was conducted in plastic $50-\mathrm{mL}$ centrifuge tubes. Ten grams of the test soil was added to each test tube along with a range of $\mathrm{NaOH}$ masses. Thirty $\mathrm{mL}$ of DI water were added to each tube, and the tubes were then vigorously shaken by hand. The $\mathrm{pH}$ of the tubes was immediately taken, and then they were placed on a laboratory rotator for continuous mixing. The tubes were removed from the rotator at the following elapsed times and the $\mathrm{pH}$ of the slurry was determined: $1,24,48$, and 96 hours.

A test was also conducted to determine if any significant reactions occur between the surfactant Tween 80 and hydroxyl species at elevated $\mathrm{pH}$ conditions. This test was conducted in plastic 50-mL centrifuge tubes. All samples contained $20 \mathrm{~mL}$ of DI water and $0.1 \mathrm{~mL}$ of Tween 80 . Eight different levels of lime addition were tested. The amount of lime added to the tubes ranged from 0.001 to 0.220 grams. The $\mathrm{pH}$ of the solution was tested several times over the course of 10 days to determine if any change in the $\mathrm{pH}$ occurred.

Tests were conducted with Tween 80 to estimate critical micelle concentration for the surfactant with the test soil. To determine the CMC, 
varying amounts of Tween 80 were added to a $50 \%\left(\mathrm{w}_{\text {soil }} / \mathrm{w}_{\text {water }}\right)$ soil slurry of DI water and the test soil in a glass centrifuge tube. The tubes were placed on a laboratory rotator overnight to allow equilibration of the surfactant in the solution. The surface tension of the liquid was then measured using a Fisher Scientific Surface Tensiomat 21 with a 6-cm test ring.

\section{Alkaline and Alkaline with ZVI Treatability Test}

Tests were conducted in 50-mL glass centrifuge tubes with $15.00 \pm 0.01 \mathrm{~g}$ of the air dried test soil, 30-mL of DI water and the appropriate amendments. Three conditions were tested: 1) a control with no additional amendments, 2) the addition of $0.03-\mathrm{g} \mathrm{NaOH}(2 \% \mathrm{w} / \mathrm{w})$, and 3) the addition of $0.03-\mathrm{g}$ $\mathrm{NaOH}$ and $0.75-\mathrm{g} Z \mathrm{VI}(5 \% \mathrm{w} / \mathrm{w})$. Each tube was placed on a laboratory rotator for one hour following the addition of the soil and amendments to ensure thorough mixing prior to initiation of the experiment (Figure 6). Tubes were removed and DI water was added to each tube. The slurry was shaken by hand and then placed back on the rotator turning at 40-rpm for continuous mixing.
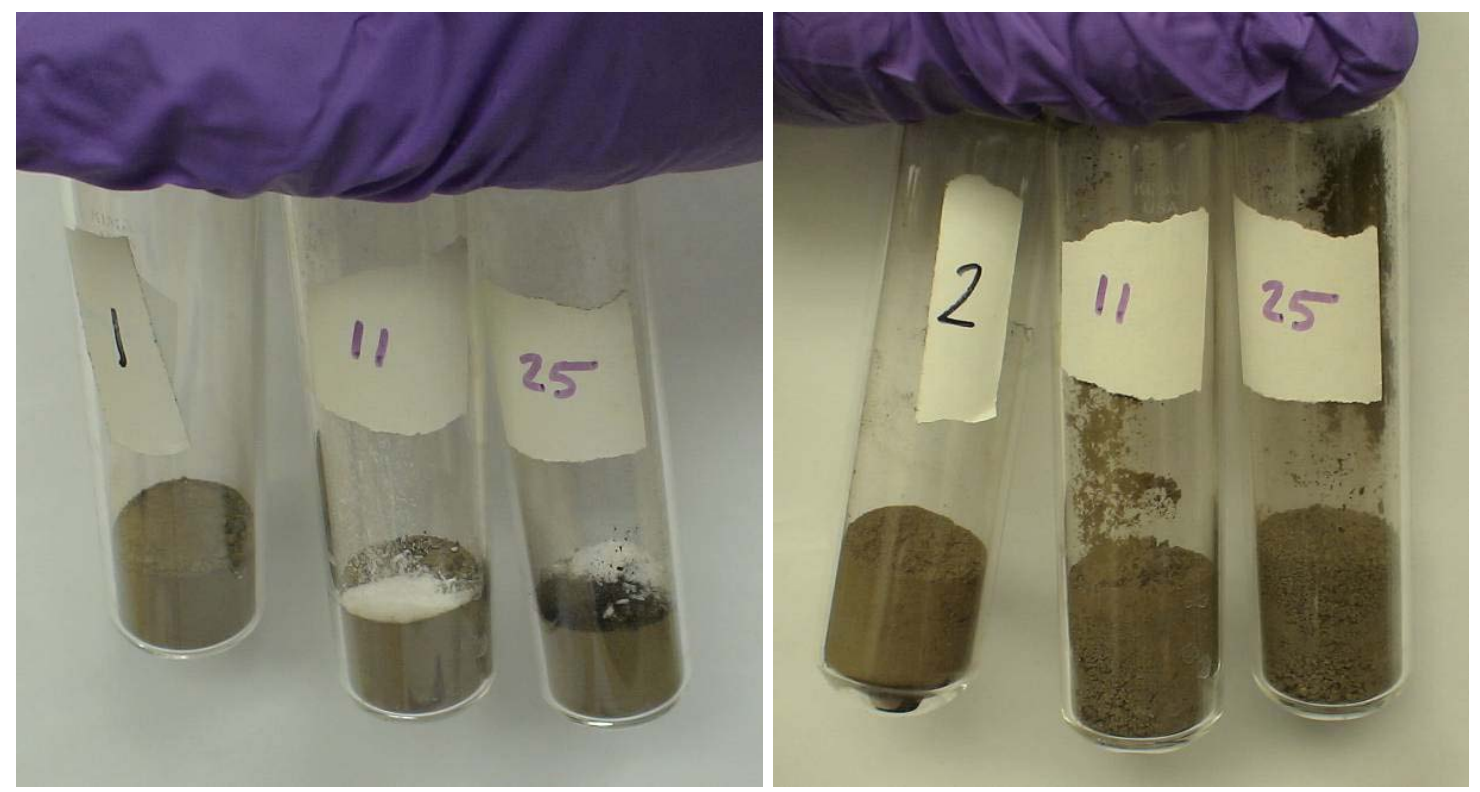

Figure 6. Dry soil with amendments before and after mixing.

Nine test tubes were created for each condition, and three tubes were sacrificed for analysis at each of the sample events. Samples were collected at 2, 4, and 10 days of elapsed time from initiation of the experiment. At each sample event the $\mathrm{pH}$ of the slurry in each tube was measured. The sacrificed tubes were then centrifuged for 30 minutes at 2000-g relative centrifugal force (RCF) (Figure 7). The supernatant and soil were collected and sent for separate extraction and analysis of PCBs. 


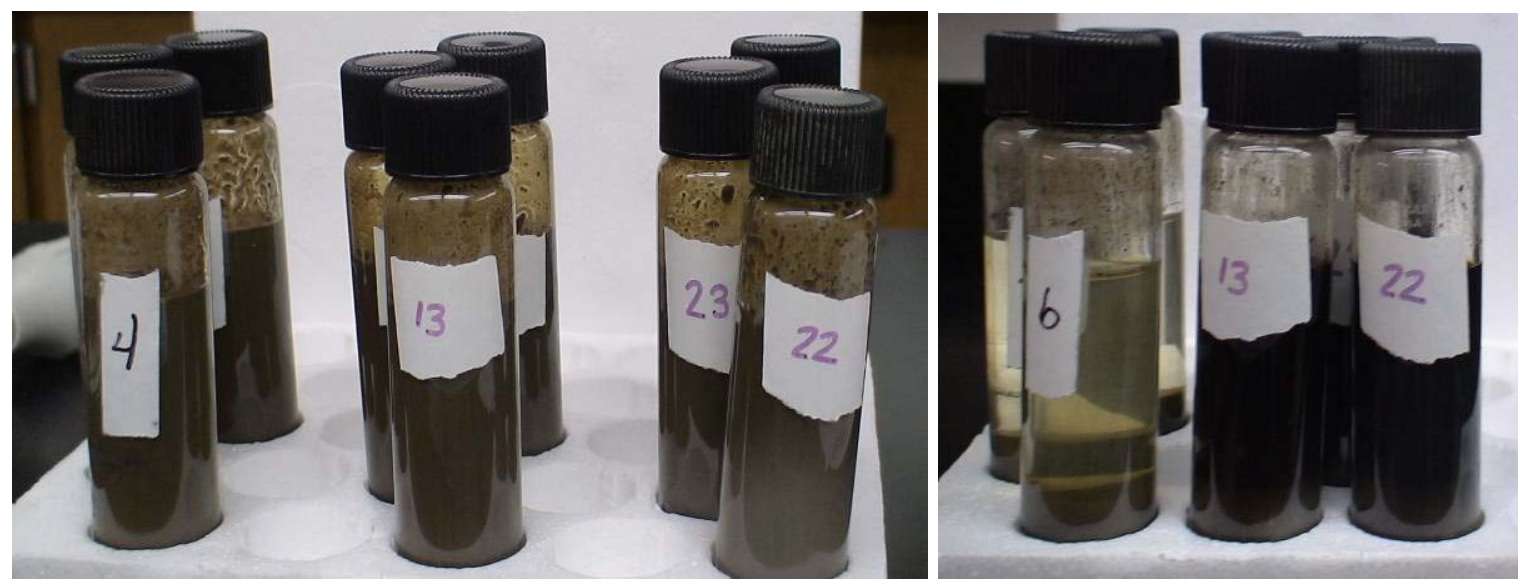

Figure 7. Treated slurry before and after centrifugation.

\section{Surfactant Addition to Alkaline and Alkaline with ZVI Treatability Test}

A second test was conducted to test the effectiveness of adding surfactant to the conditions of the previous test. The change in conditions from the first test was the addition of 30-mL of 75-g/ L Tween 80 solution to the alkaline and alkaline with ZVI conditions in place of DI water. Twelve test tubes were created for the control condition, and nine tubes were created for each of the active conditions. Three tubes were sacrificed for analysis at each of the sample events. Samples were collected 1 hour from the initiation of the test for the control condition, and 2, 4, and 10 days of elapsed time from the initiation of the experiment for all conditions. The soils from these slurries were air-dried prior to extraction for PCB analysis.

\section{Alkaline Hydrolysis of PCBs in Water}

Tests were conducted to determine if alkaline hydrolysis of PCBs can actually occur at or near standard temperatures and pressures in a significant timeframe in the absence of soil. Tests were conducted at room temperature (approx. $22^{\circ} \mathrm{C}$ ) in 250 - $\mathrm{mL}$ amber glass bottles with Teflonlined septum caps. The bottles were placed on an orbital shaker operating at $250 \mathrm{rpm}$. The PCB solution used was a $100-\mathrm{\mu g} / \mathrm{mL}$ methanol solution of Aroclor 1254 created from a PCB standard. For the control condition, 99-mL of DI water and $1 \mathrm{~mL}$ of PCB solution was added to each of four bottles. For the alkaline condition, $99 \mathrm{~mL}$ of $0.25-\mathrm{M} \mathrm{NaOH}$ solution and $1 \mathrm{~mL}$ of PCB solution was added to each of four bottles. At the time this experiment was conducted, we found that our analytical budget would not allow us to triplicate the analyses. However, since the goal was to simply determine whether removal was occurring, we decided we could accomplish this with an unreplicated study. The contents of one bottle from each 
condition were extracted at $0,1,3$, and 7 days. After decanting the sample, each bottle was triple-rinsed with methylene chloride, which was added to the extract from the sample.

\section{Persulfate Degradation of PCBs}

Tests were conducted to determine if either heat- or alkaline-activated persulfate are capable of degrading PCBs. Tests were conducted in 250-mL amber-glass Boston round bottles. $100 \mathrm{~mL}$ of DI water and $100 \mu \mathrm{L}$ of 50- $\mathrm{kg} / \mathrm{mL}$ Aroclor 1254 stock solution was added to each bottle to create an approximate initial Aroclor 1254 concentration of $50 \mu \mathrm{g} / \mathrm{L}$. Four bottles were created for each of three conditions: control, heat-activated, and alkaline-activated. Samples were collected and extracted at the initiation of the test and 1, 5, and 8 days after initiation. One bottle was sacrificed for analysis of PCBs at each sample interval for each condition.

For the control condition an additional $20 \mathrm{~mL}$ of DI water was added to the bottles, and the bottles were kept in a box shielded from light at room temperature. $20-\mathrm{mL}$ of a $0.5-\mathrm{M}$ sodium persulfate solution was added to each bottle of the active conditions. Bottles for the heat-activated persulfate condition were maintained at $50^{\circ} \mathrm{C}$ in an incubator. These bottles were removed from the incubator and cooled in a refrigerator prior to extraction for PCB analysis. Alkaline conditions were created and maintained in bottles for the alkaline-activated condition by the addition of $741 \mathrm{mg}$ of calcium hydroxide (hydrated lime). These bottles were kept in a box with those of control condition. The solution $\mathrm{pH}$ of these bottles was checked and neutralized with $0.45 \mathrm{~mL}$ of $37 \%$ hydrochloric acid prior to extraction for PCB analysis.

\section{Effect of High Alkalinity on PCB Extractions}

Tests were conducted to estimate the effect of highly alkaline conditions created by sodium hydroxide and hydrated lime on the extraction of PCBs from the test soil. Tests were conducted in $50-\mathrm{mL}$ glass centrifuge tubes. $15.00 \pm 0.01 \mathrm{~g}$ of air-dried test soil and 30-mL of DI water were added to each tube along with the appropriate amendments. Three test tubes were created for each of five test conditions with the following amendment additions:

1. no additional amendments (control);

2. $0.30-\mathrm{g} \mathrm{NaOH}(\mathrm{NaOH})$, 
3. $0.30-\mathrm{g} \mathrm{NaOH}$ plus $37 \% \mathrm{HCl}$ prior to extraction ( $\mathrm{NaOH}-$ neutral),

4. $0.45-\mathrm{g} \mathrm{Ca}(\mathrm{OH})_{2}$ (lime),

5. $0.45-\mathrm{g} \mathrm{Ca}(\mathrm{OH})_{2}$ plus $37 \% \mathrm{HCl}$ prior to extraction (lime-neutral).

All tubes were placed on a laboratory rotator at room temperature for mixing. After 8 days of mixing, the $\mathrm{pH}$ of the slurry in the tubes was recorded. The $\mathrm{pH}$ of 3 tubes from both the $\mathrm{NaOH}$ and lime conditions was neutralized by the addition of $37 \%$ hydrochloric acid, and the tubes were rotated for an additional hour and the $\mathrm{pH}$ rechecked. This procedure was repeated until a sustained $\mathrm{pH}$ of less than 8 was achieved. Following $\mathrm{pH}$ neutralization all tubes were centrifuged, and the water and soil were separated for extraction and analysis for PCBs. The soil samples were dried overnight in a laboratory oven set to $25^{\circ} \mathrm{C}$ prior to conducting the extraction. The oven temperature may have ranged from 22 to $28^{\circ} \mathrm{C}$ during the drying process. 


\section{Results and Discussion}

\section{Alkaline Demand of Soil and Amendment Interactions}

Initial tests were conducted to determine the level of $\mathrm{NaOH}$ addition necessary to maintain a $\mathrm{pH}$ of approximately 12.5 in the slurry of the test soil. Results indicated that only a marginal increase of $\mathrm{pH}$ in the slurry would be achieved by the addition of $\mathrm{NaOH}$ at a level in excess of $2 \%$ of the dry weight of the soil (Figure 8). Therefore, an amendment level of $2 \%$ $\mathrm{NaOH}$ was chosen for the PCB degradation experiments.

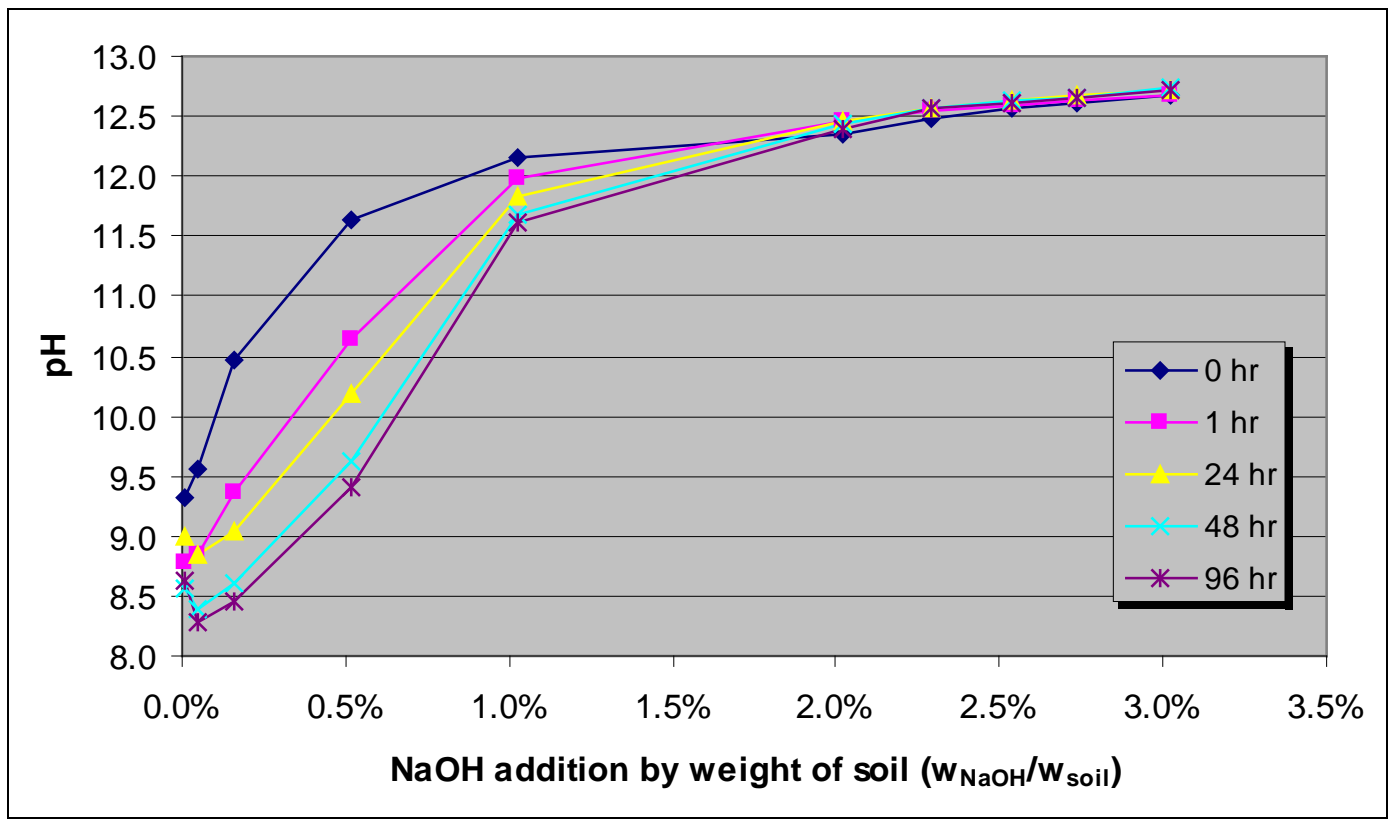

Figure 8. Alkaline demand of test soil.

Tests were conducted to estimate the level of surfactant addition to the soil slurry necessary to achieve a critical micelle concentration (CMC). The results of these tests are shown in Figure 9 and indicated that for this test soil approximately $15 \%(\mathrm{w} / \mathrm{w})$ of Tween 80 addition is necessary to achieve a CMC.

The test for interaction between the surfactant Tween 80 and $\mathrm{OH}$ species at high $\mathrm{pH}$ conditions did not indicate any obvious rapid reaction by the formation of either gas bubbles or exothermic heat. However, analysis of the $\mathrm{pH}$ results does indicate that a slow reaction is occurring with the $\mathrm{OH}$ species over time. Figure 10 shows that through the 3-day sample event 


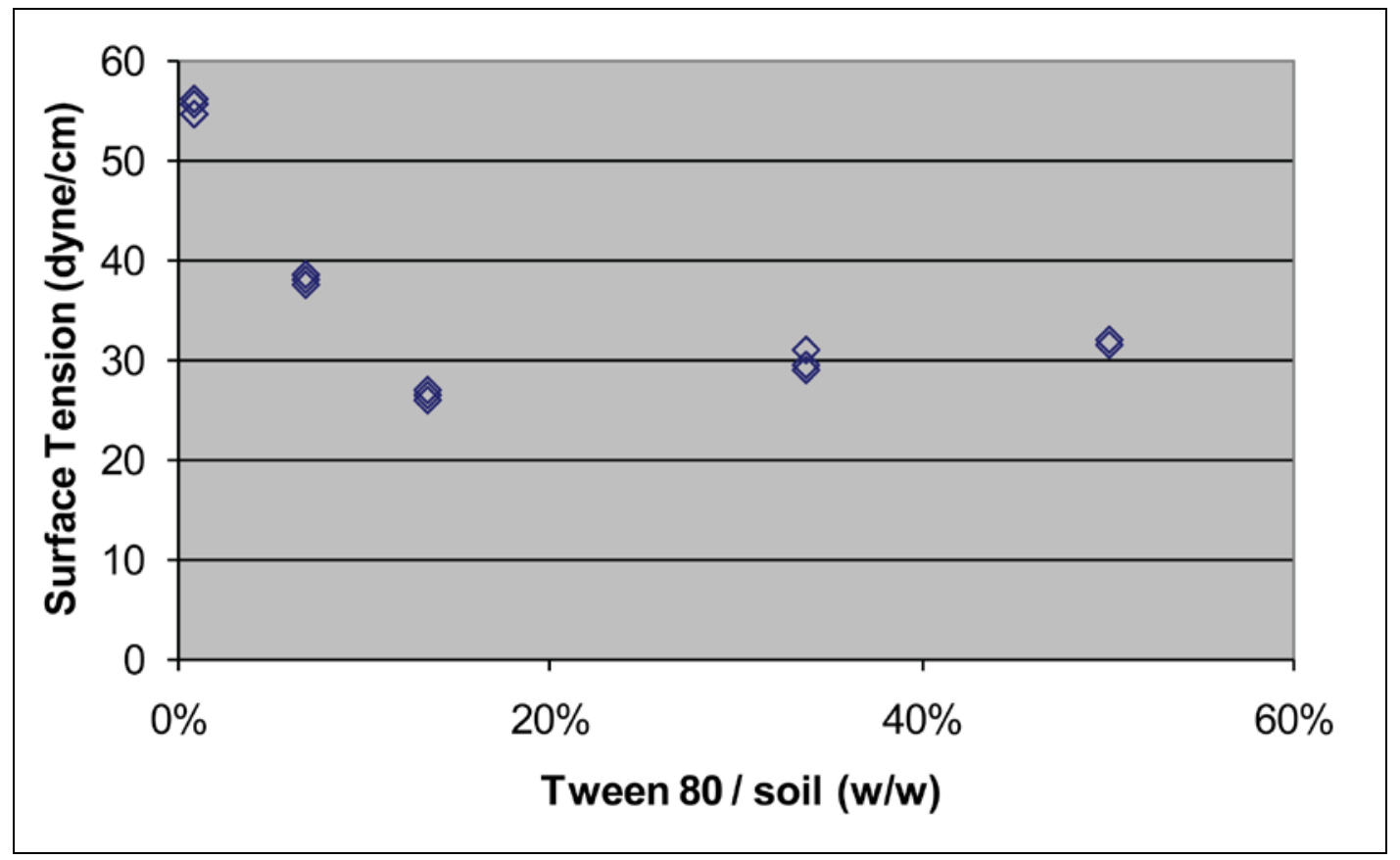

Figure 9. Estimate of Tween $80 \mathrm{CMC}$ with soil.

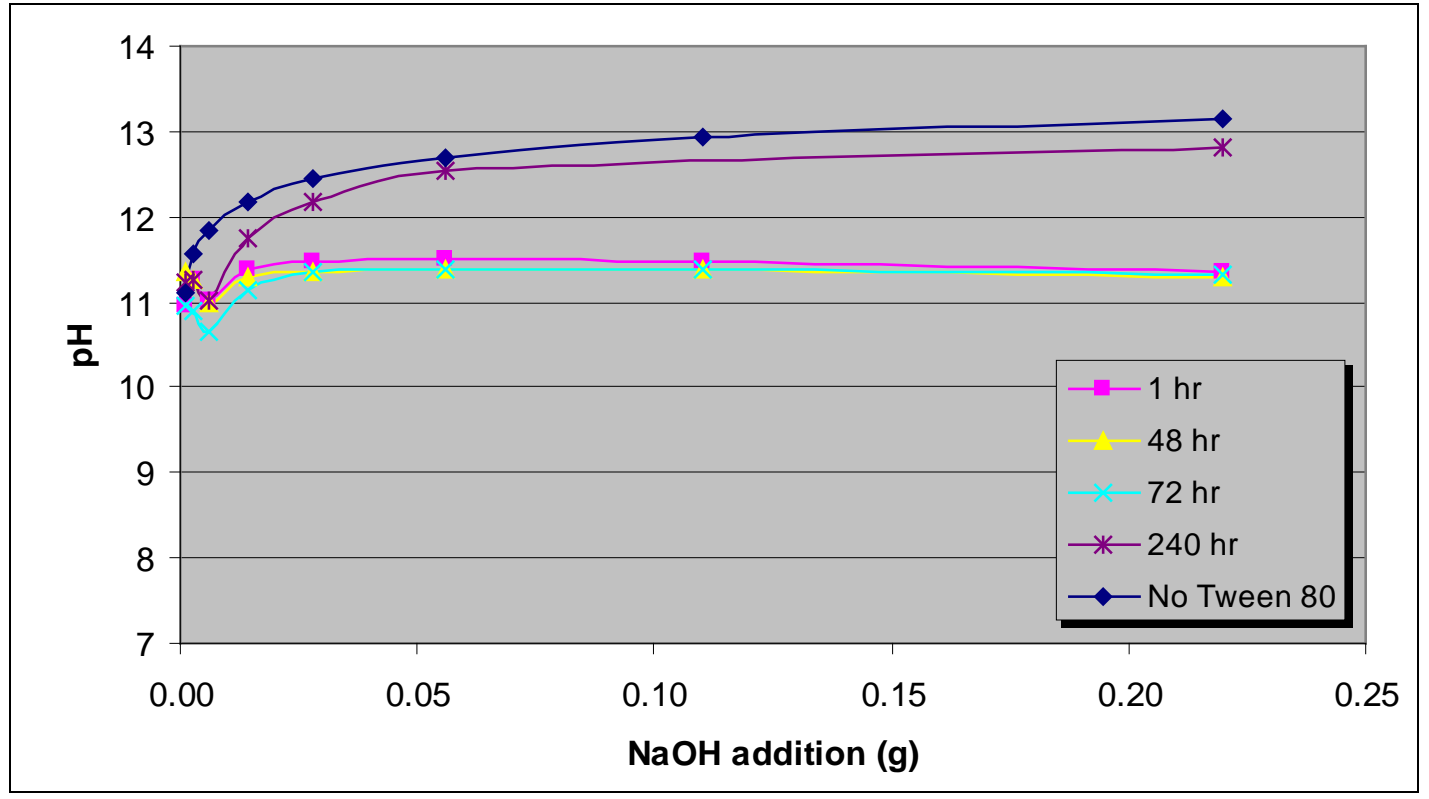

Figure 10. Amendment interaction.

the $\mathrm{pH}$ was significantly lower than the theoretical $\mathrm{pH}$ value if no surfactant was added. The sample collected at 10 days indicated that the $\mathrm{pH}$ measured in the tubes was near the theoretical value calculated. This indicates that whatever reaction was occurring with the $\mathrm{OH}$ species was complete or nearing completion. The fate of the surfactant in this test is not known, but the test does indicate that no dangerous reaction will occur with this surfactant at the elevated $\mathrm{pH}$ conditions used in these tests. 


\section{Alkaline and Alkaline with ZVI Treatability Tests}

Initial analytical results of treatability tests with alkaline and alkaline with ZVI conditions indicated a very high reduction of the PCB concentrations in all conditions including the control samples; this appeared to correlate with the moisture content of the soil. Based on this information, a second soil sample from each tube was air-dried and extracted for analysis. Air-drying of all soil samples took place in a laboratory oven with an ambient temperature of $25^{\circ} \mathrm{C}$. Samples were also collected again from the drum of test soil. These samples were also air-dried and extracted with the slurry samples. Figure 11 shows the results of air-drying on the extraction and analysis of the control samples. An analysis of variance (ANOVA) of these results indicates that a significant difference exists between the means of the data sets $(\mathrm{P}<0.001)$. A pairwise comparison (Tukey Test) of the means shows that the only means that did not show a significant difference were those from the resampled drum and those of the control slurries that were air-dried $(P=0.267)$. The difference between the original samples from the drum and the samples collected from the drum at a later date and air-dried may be due to volatilization of the PCBs during the air-drying process.

Although the air-drying of samples from the drum appears to have reduced

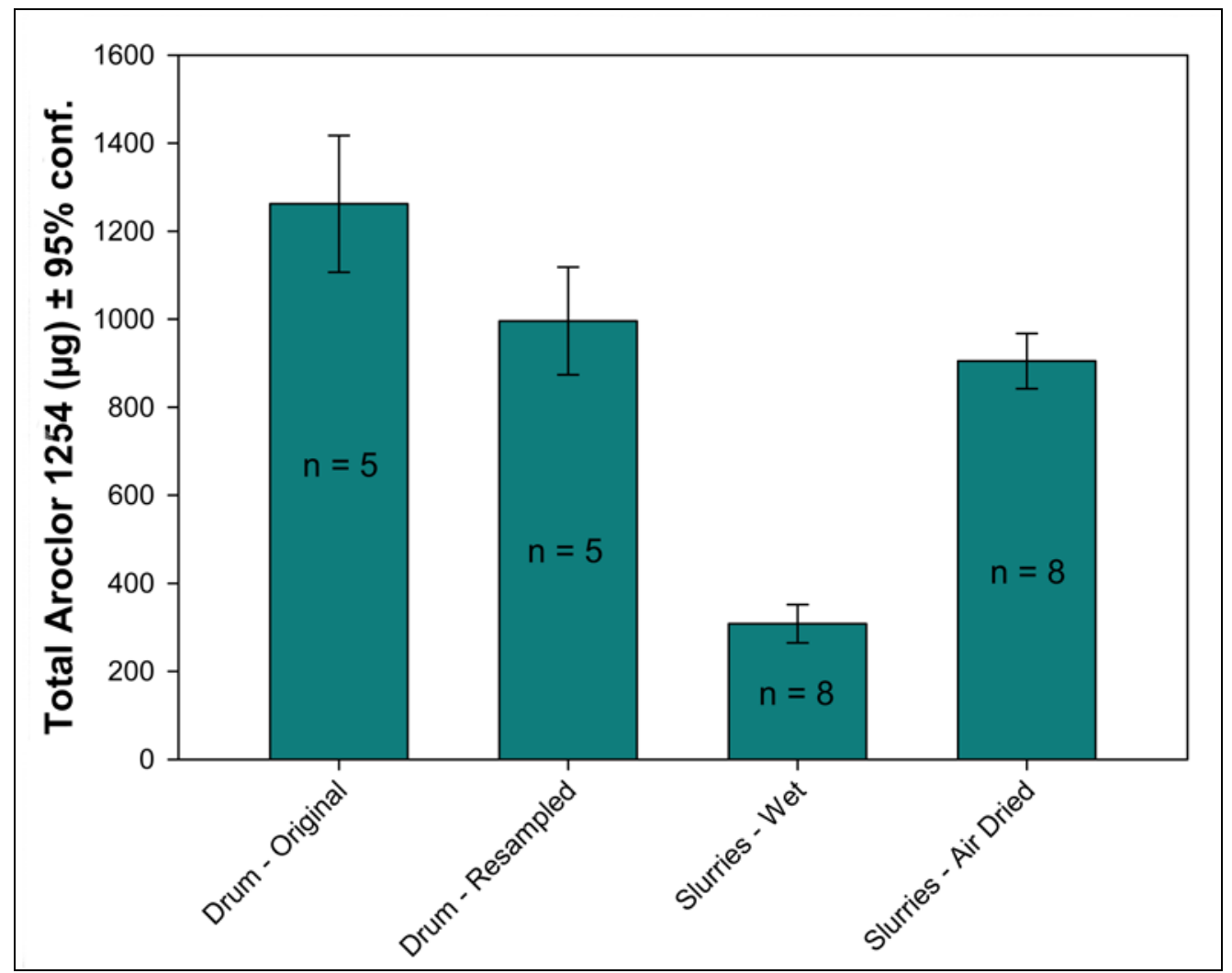

Figure 11. Effect of air-drying on control samples. 
the PCB concentration results by only approximately $20 \%$, this outcome was far better than the approximately $75 \%$ reduction realized from extracting the soil in a wet condition. Based on these results, all further soil samples were dried.

The results of total PCBs from the air-dried samples are illustrated in Figure 12. The initial concentrations used for all conditions were the results from resampling the homogenized drum of test soil and air-drying those samples prior to extraction. Analytical results of control samples indicated that no detectable PCBs were desorbed from the soil into the water of the slurry. An ANOVA of the means of the control samples at different elapsed times showed that there was not a statistically significant difference between any of the elapsed times sampled, $\mathrm{P}=0.104$.

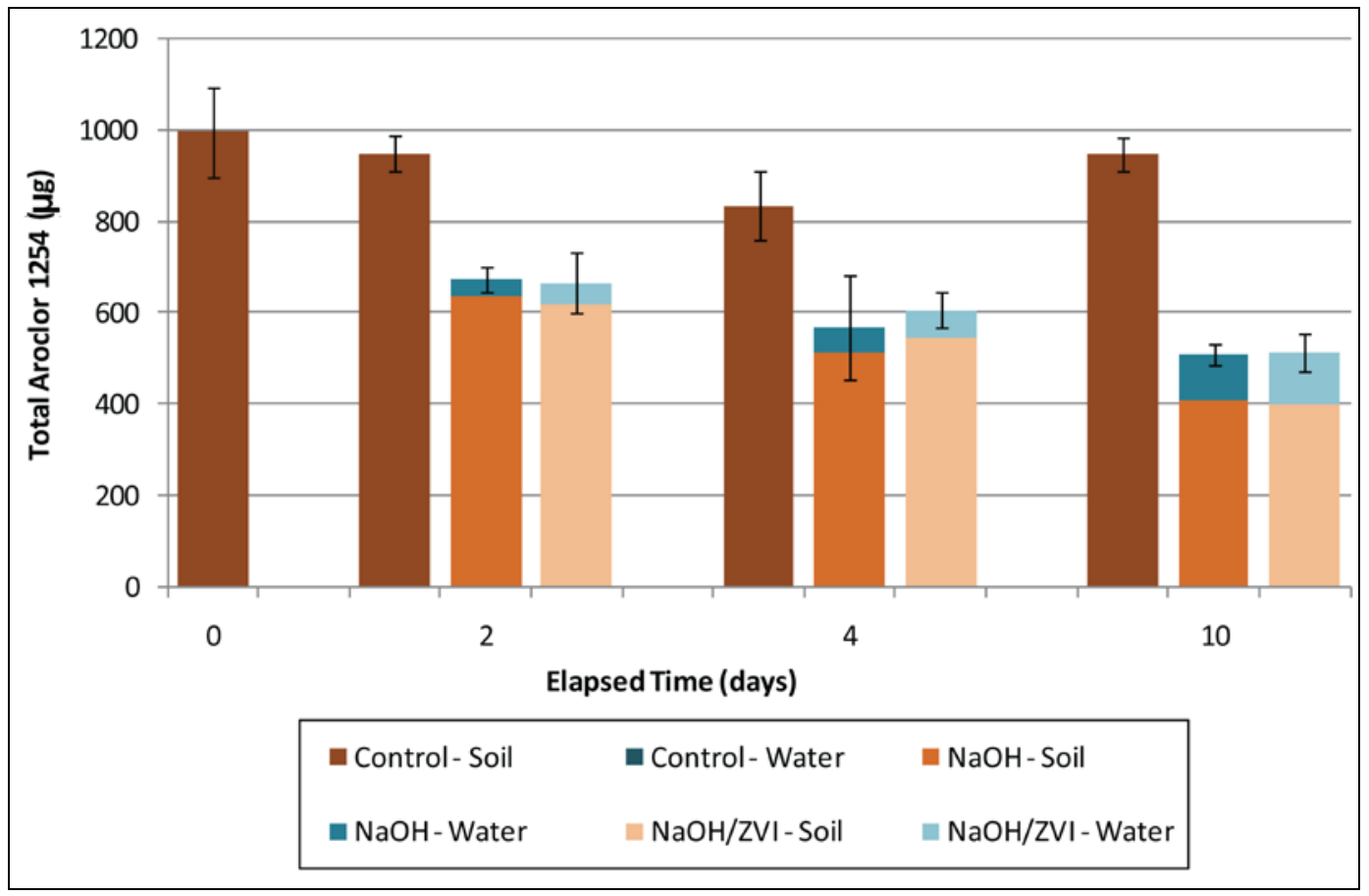

Figure 12. Total PCB results for alkaline and alkaline with ZVI tests.

Results from the two treatment conditions did show a significant loss of PCBs from the slurry. Analysis of the data showed that an exponential (first-order) decay of PCB mass approaching a minimum that was other than zero provided the best fit of the data. This is the typical case for hydrophobic organic compounds adsorbed to soil. An illustration of the regressions of total PCB mass results are provided in Figure 13 for the alkaline conditions and Figure 14 for the alkaline with ZVI conditions. 


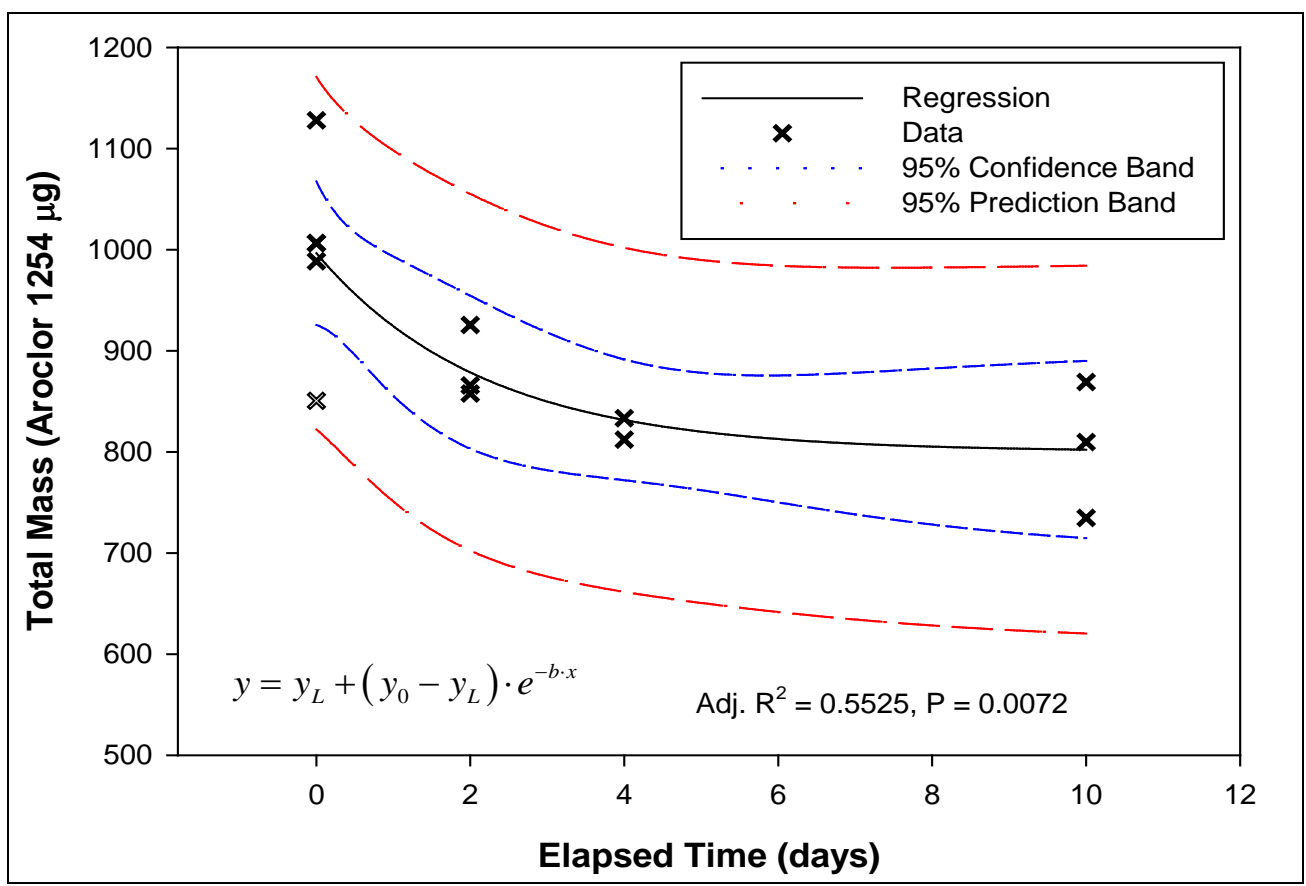

Figure 13. Regression of total PCBs - alkaline treatment.

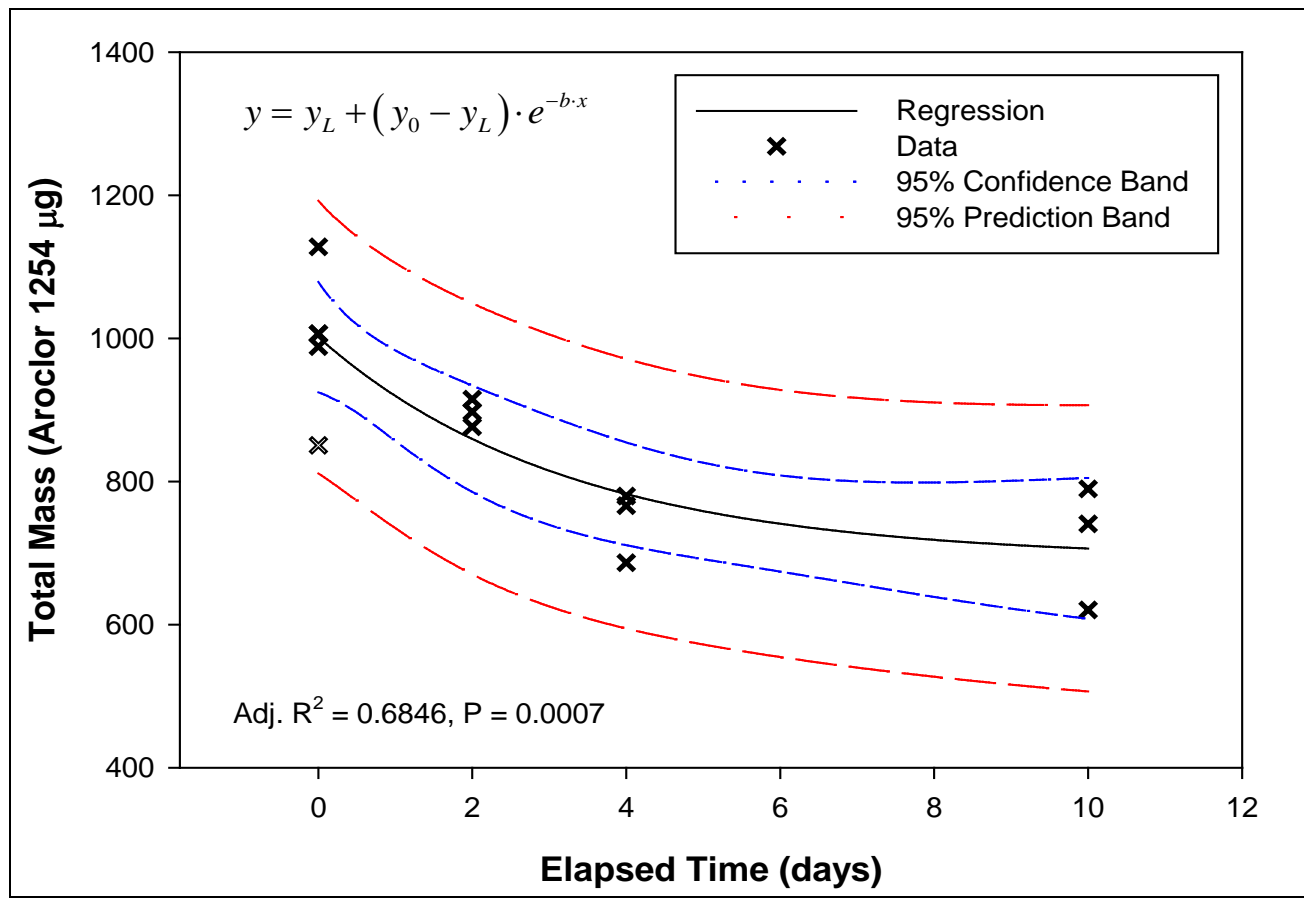

Figure 14. Regression of total PCBs - alkaline with ZVI treatment.

The results from the final sample interval and the regressions of the treatments are consolidated in Table 2. An ANOVA with a Tukey Test comparing the initial PCB mass and the final results (i.e. 10-day samples) of each condition indicated that the control condition did not result in any significant change; however, the two treatments did significantly change 
the total PCB mass in the test tubes. No significant difference was detected between the alkaline and alkaline with ZVI conditions, but the actual oxidation-reduction potential (ORP) of the solution before and after ZVI addition was not measured. It is estimated that with 10 days of treatment, the alkaline and alkaline with ZVI treatments can reduce the mass of total PCBs by $20 \%$ and $30 \%$, respectively.

Table 2. Consolidated results of total PCB mass.

\begin{tabular}{|c|c|c|c|c|c|}
\hline \multirow[b]{2}{*}{ Condition } & \multirow{2}{*}{$\begin{array}{l}\text { Initial } \\
(n=5)\end{array}$} & \multirow{2}{*}{$\begin{array}{l}10 \text { days } \\
(n=3)\end{array}$} & \multirow{2}{*}{$\begin{array}{l}\text { Removal } \\
@ 10 \text { days }\end{array}$} & \multicolumn{2}{|c|}{ Estimated by Nonlinear Regression } \\
\hline & & & & Final & Removal \\
\hline Control & $996 \pm 99$ & $947 \pm 38$ & $49 \pm 106$ & & \\
\hline Alkaline & $996 \pm 99$ & $805 \pm 67$ & $191 \pm 120$ & $\begin{array}{l}800 \pm 160 \\
(n=13, \text { d.f. }=10 \\
P=<0.0001)\end{array}$ & $\begin{array}{l}196 \pm 192 \\
(n=13, \text { d.f. }=10 \\
P=0.0042)\end{array}$ \\
\hline $\begin{array}{l}\text { Alkaline } \\
+\mathrm{ZVI}\end{array}$ & $996 \pm 99$ & $717 \pm 87$ & $279 \pm 132$ & $\begin{array}{l}692 \pm 246 \\
(n=14, \text { d.f. }=11 \\
P=<0.0001)\end{array}$ & $\begin{array}{l}310 \pm 343 \\
(n=14, \text { d.f. }=11 \\
P=0.0011)\end{array}$ \\
\hline $\begin{array}{c}\text { All valu } \\
\text { d.f. - }\end{array}$ & $\begin{array}{l}\text { oclor } 125 \\
\text { freedom }\end{array}$ & td. dev. & & & \\
\hline
\end{tabular}

\section{Surfactant Addition to Alkaline and Alkaline with ZVI}

A second series of treatability tests were run to determine if the addition of a non-ionic surfactant, Tween 80, would enhance the removal and degradation of PCBs from the test soil. The results of total PCB mass are presented in Figure 15. No significant change was seen in any of the conditions; this indicates that the addition of a surfactant was not beneficial to these treatments. However, the surfactant did appear to solubilize significantly more PCBs when compared to the results of the previous test (Figure 12).

As with the previous treatability test, all soil samples were air-dried prior to performing the extraction of PCBs for analysis. Further, based on concerns raised about the interference of alkaline conditions on the extraction of PCBs, the $\mathrm{pH}$ was neutralized in only the slurries of the 10day tubes from the alkaline/ Tween 80 condition for comparison. An ANOVA with a Tukey Test comparing the different time intervals sampled of the alkaline/ Tween 80 conditions showed that the 10-day samples were significantly $(\mathrm{P}=0.002)$ different from the other sample intervals. This indicates that the alkaline conditions of the slurries may be impacting the extraction process. 


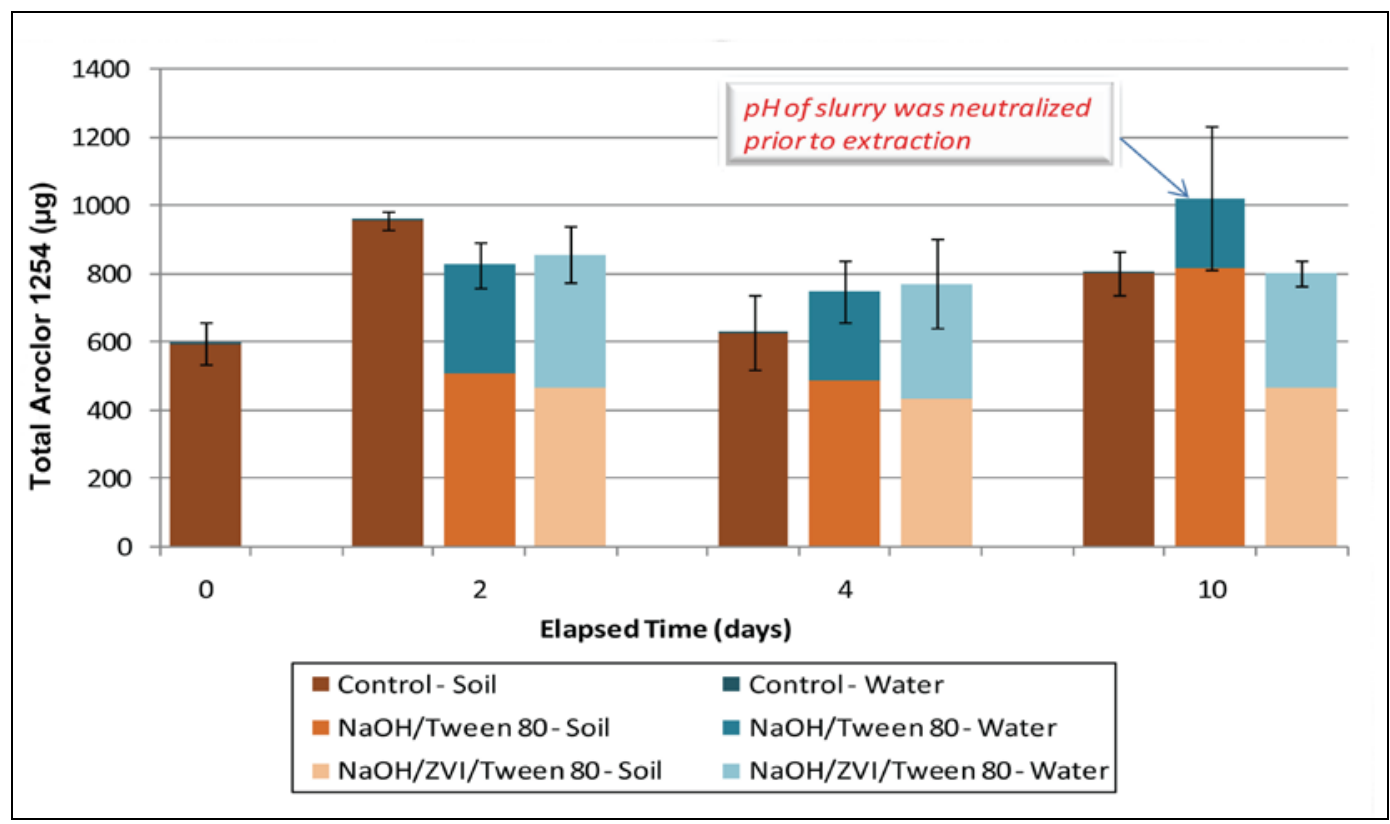

Figure 15. Total PCBs of Tween 80 addition to Alkaline and Alkaline plus ZVI Treatment.

\section{Alkaline Hydrolysis of PCBs in Water}

Cassidy (2010) suggested that the use of lime in soil may interfere with the extraction of PAHs from soil or the analysis of the process. Because this report casts some doubt on the validity of results obtained in the first treatability test, additional tests were conducted to determine if alkaline hydrolysis of PCBs can occur in a strictly aqueous environment near standard temperature and pressure. The results of these tests are illustrated in Figure 16. A comparison between the control and alkaline conditions was performed with a Wilcoxon signed rank test. This comparison indicated that the change that occurred with the treatment is not great enough to exclude the possibility that it is due to random error $(\mathrm{P}=0.375)$.

\section{Persulfate Degradation of PCBs in Water}

Tests were conducted to determine if activated persulfate is a possible treatment mechanism for PCBs. Two types of persulfate activation were tested, heat $\left(50^{\circ} \mathrm{C}\right)$ and alkaline ( $\left.\mathrm{pH}=12.5\right)$, on aqueous solutions of PCBs. The PCB analysis results of these tests are presented in Figure 17. No significant correlation was found between the PCB concentration in the control samples and time $(\mathrm{P}=0.973)$, which is an indication that the control condition did not change with time. The concentrations from the control conditions also remained close to the calculated concentration added to the samples. 


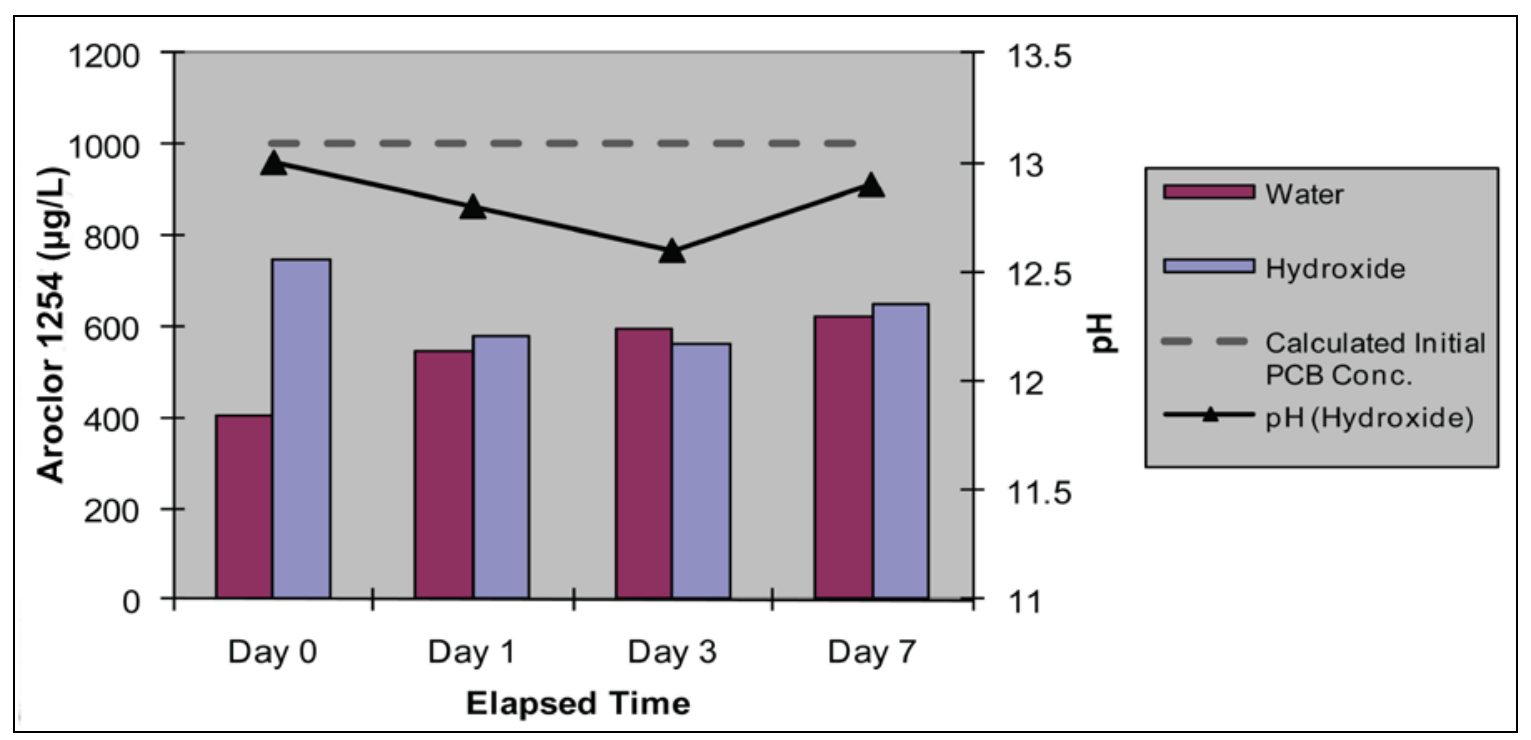

Figure 16. Alkaline hydrolysis of PCBs in aqueous solution.

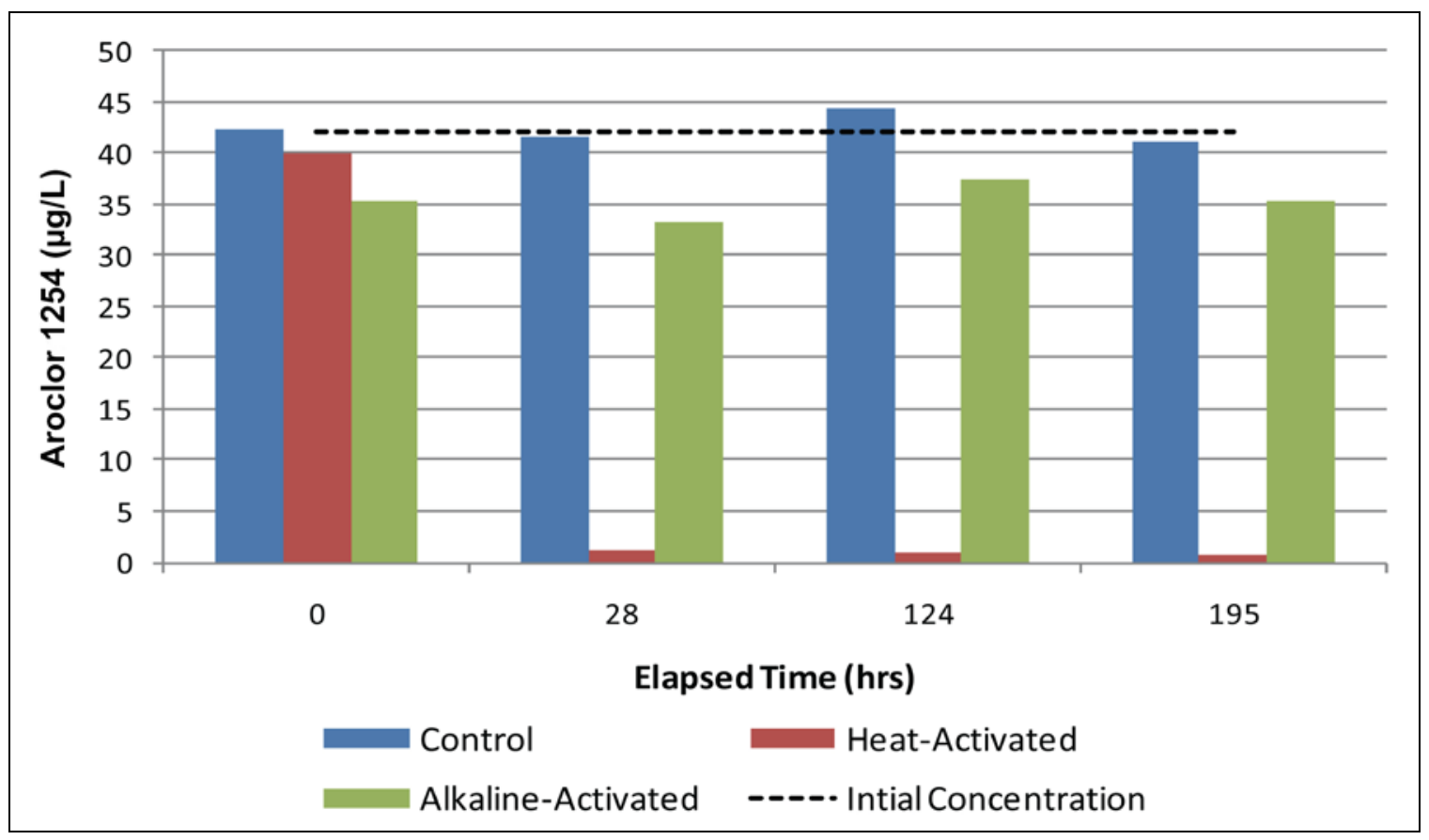

Figure 17. PCB results of persulfate tests.

Degradation of PCBs by heat-activated persulfate was rapid and both the Aroclor 1254 and persulfate were nearly gone after 2 days of reaction time (Figure 18). The persulfate also disappeared much more rapidly than anticipated, based on rates predicted by Kolthoff (1951), which may indicate that some additional interactions between the persulfate and the PCBs may be occurring other than that of the sulfate radicals generated by the heat. The 1 st-order regression of the PCB results indicated a very strong correlation, $\mathrm{R}^{2}=0.9988$, with a degradation rate $(\mathrm{k})$ of $0.128 \mathrm{~h}^{-1} \pm 0.115$. 


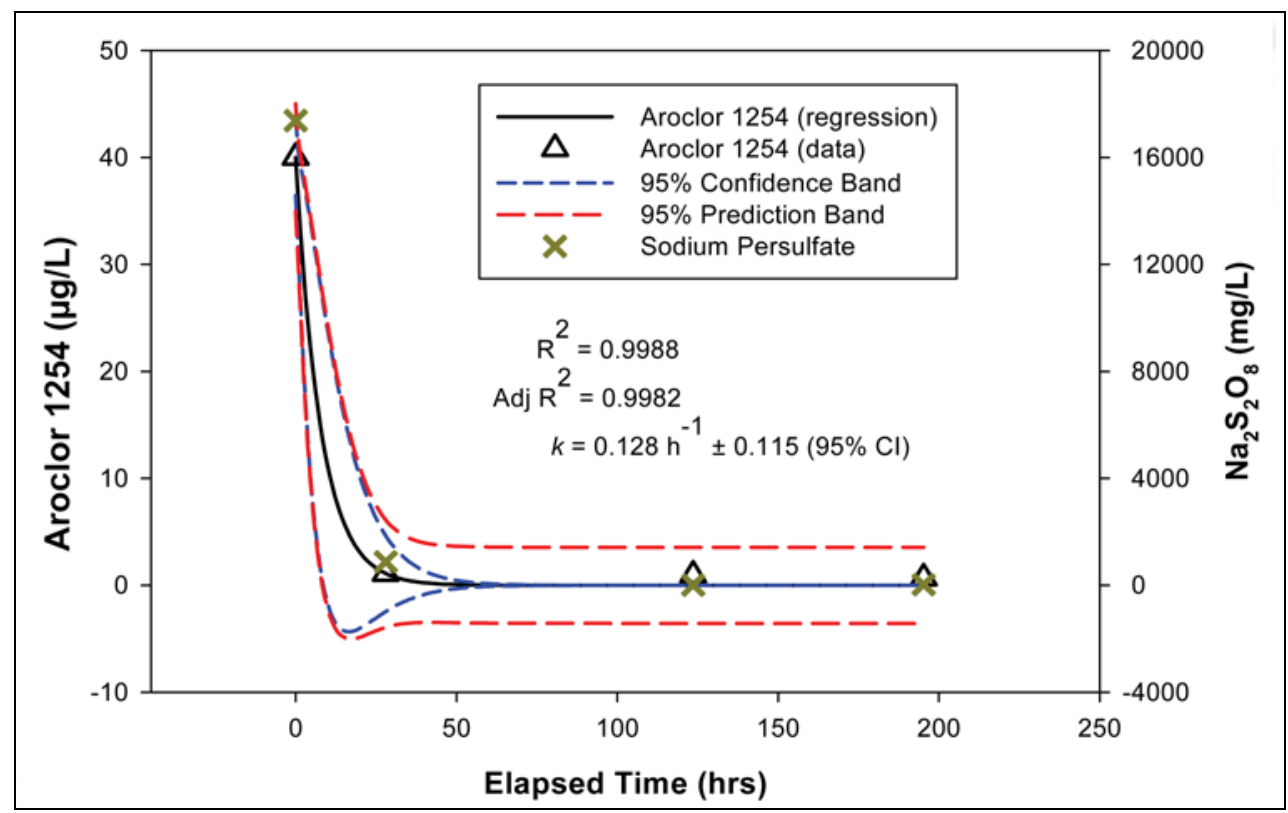

Figure 18. Degradation of PCBs by heat-activated $\left(50^{\circ} \mathrm{C}\right)$ persulfate.

PCB analysis results from the alkaline-activation of persulfate at a pH of 12.5 did not show any significant change in the concentration of Aroclor 1254 ( $\mathrm{P}=0.59$ ), as determined by a linear regression (Figure 19). Analysis of the persulfate data (Figure 20) by a 1st-order regression showed that the alkaline conditions did react with the persulfate. The persulfate concentration was reduced by approximately $32 \%$ over the 8 days of the experiment.

\section{Effect of High Alkalinity on PCB Extractions}

Tests were conducted to evaluate the effect of highly-alkaline conditions on the extraction of PCBs from soil. The results of these tests are presented in Figure 21. An ANOVA of the total PCB level showed no significant difference between any of the conditions $(P=0.107)$. Based on the findings from PCB extractions in the first treatability tests, all the soils were air-dried prior to extraction. This may be an indication that the presence of water and alkalinity may interfere with the extraction process. The only condition that indicated a significantly different result was the $\mathrm{NaOH}$ without $\mathrm{pH}$ neutralization. This condition showed a significant mass of PCB was present in the water. 


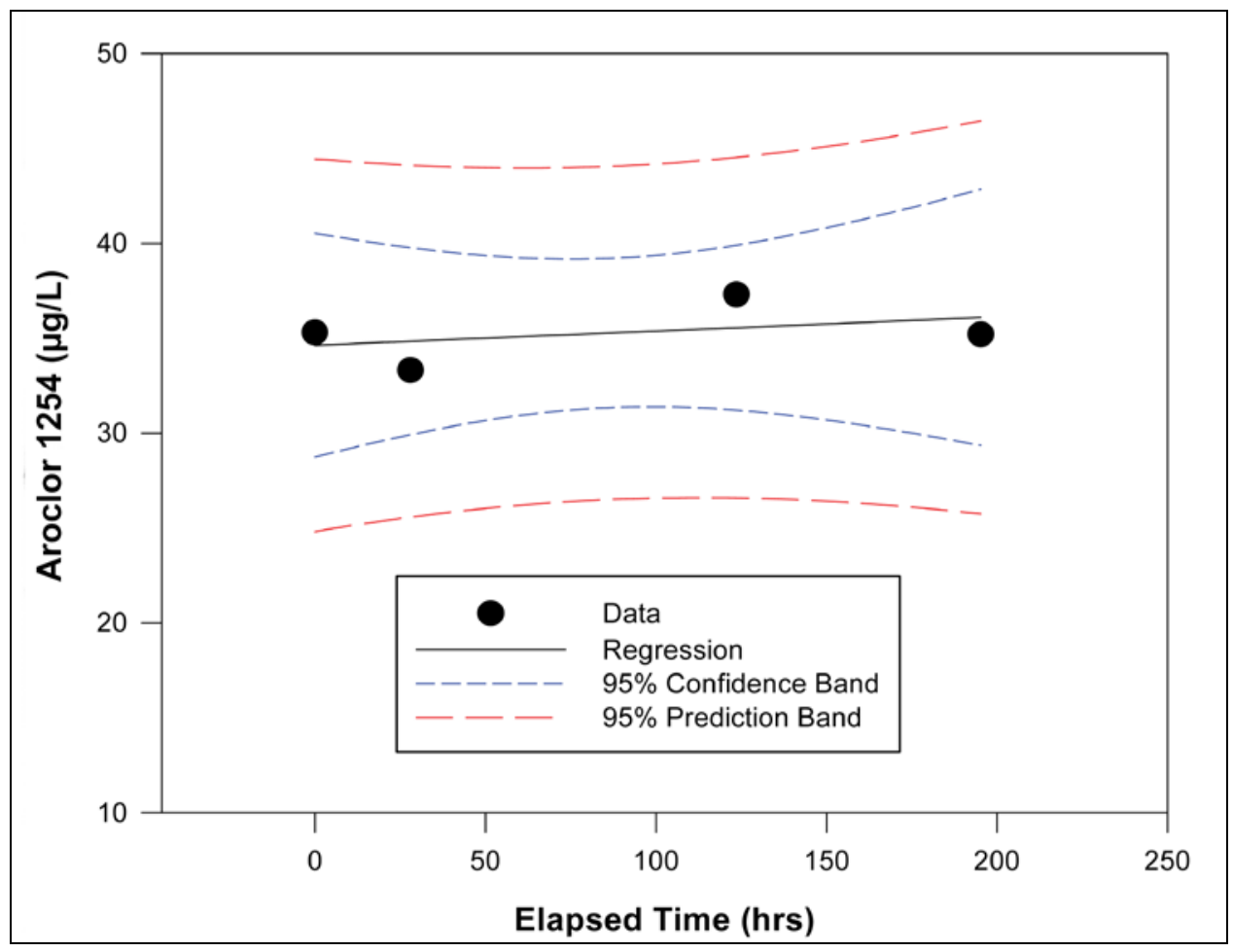

Figure 19. PCB results for alkaline-activated persulfate.

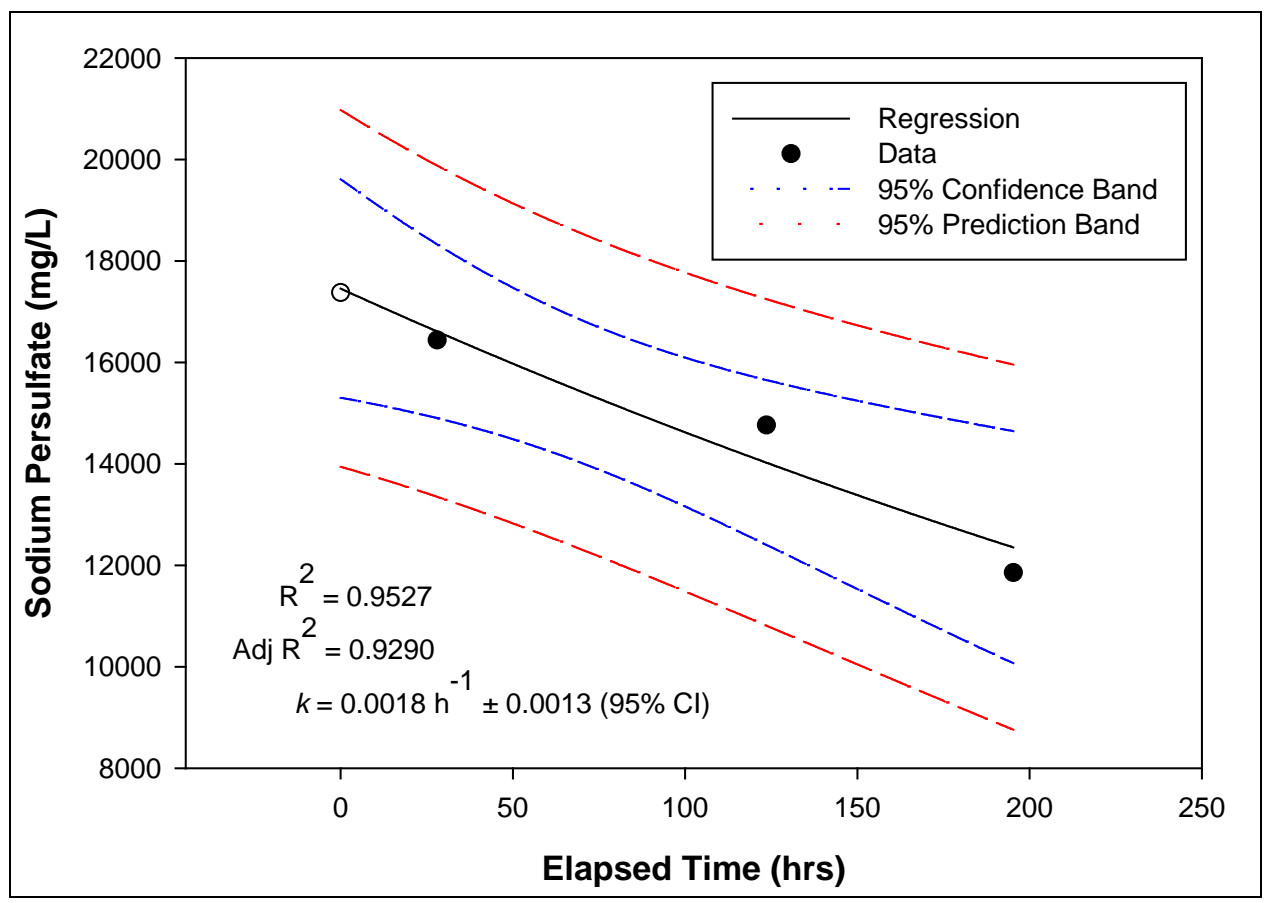

Figure 20. Activation of persulfate by alkaline $(\mathrm{pH}=12.5)$ conditions. 


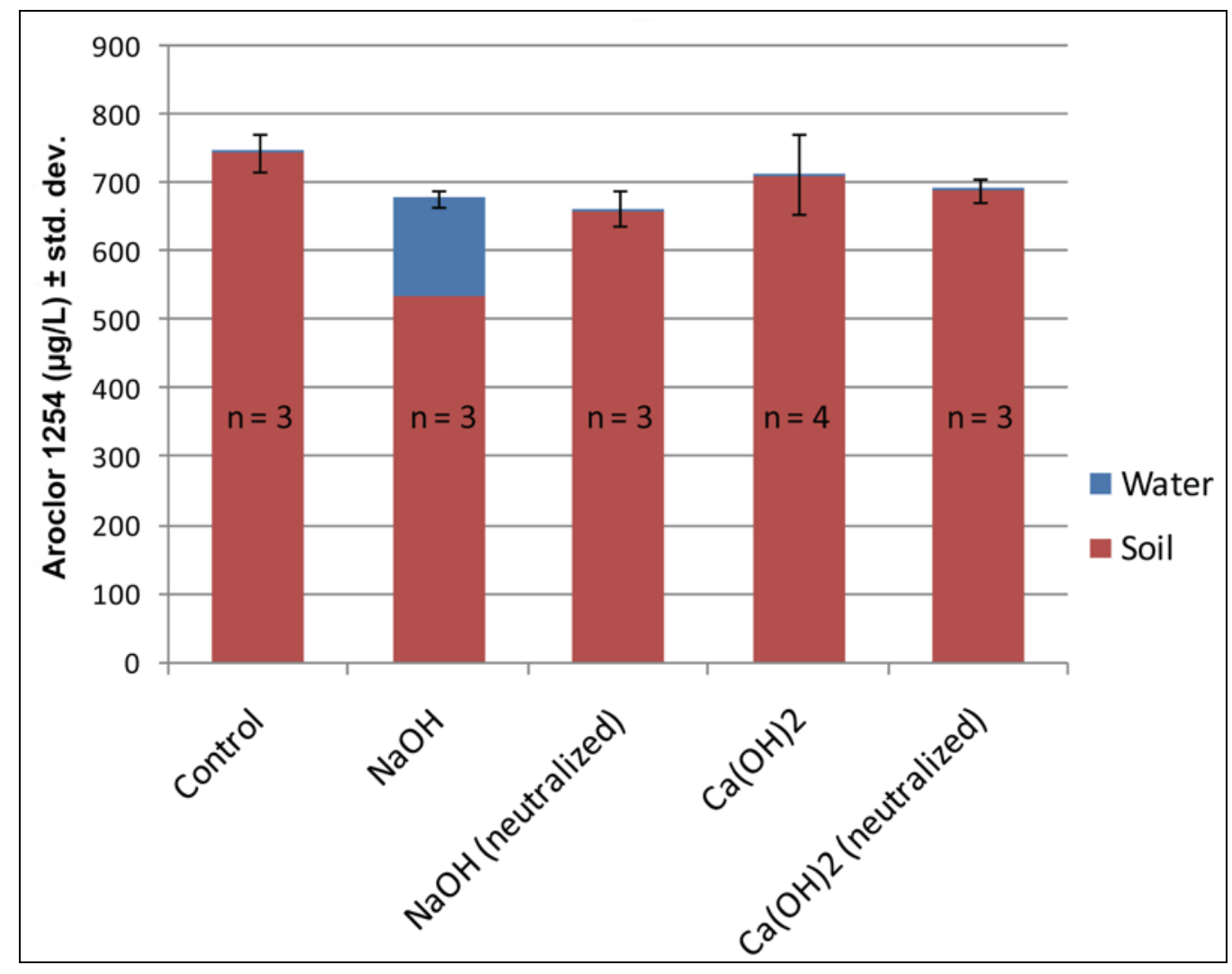

Figure 21. PCB results of alkalinity effect on extraction. 


\section{Conclusions}

Based on the test results, it appears that a 10-day treatment with alkaline conditions using $\mathrm{NaOH}$ (2\%) or $\mathrm{NaOH}$ with ZVI decreased, by 20 to 30\%, total PCBs. Neither of the two conditions yielded any significant difference from one another in terms of the level of treatment. The addition of a nonionic surfactant, Tween 80 , to the treatments with $\mathrm{NaOH}$ and $\mathrm{NaOH}$ with ZVI did not appear to increase the removal of PCBs from the test soils.

However, a check conducted during this test indicated that neutralization of the slurry $\mathrm{pH}$ can significantly impact the PCB results. The solution phase experiment supported the conclusion by Cassidy that removal of PCBs during alkaline hydrolysis may be due to extraction interferences.

Results from tests with the oxidant sodium persulfate indicate that heatactivated persulfate can rapidly degrade PCBs in an aqueous solution. However, alkaline-activated persulfate at a $\mathrm{pH}$ of 12.5 near standard temperature and pressure did not show any significant degradation of PCBs over a period of 7 days. Heat activation of persulfate is known to efficiently produce the sulfate radical, which is a very strong oxidizing species. In contrast, the resulting oxidizing species generated from alkaline activation of persulfate is less clear and apparently cannot effectively degrade PCBs.

A final test was conducted to determine the impact of highly alkaline conditions on the extraction of PCBs from the test soil. This test indicated that the neutralization of the soil slurry did not significantly change the results; however, soils from these slurries were thoroughly dried with an oven prior to extraction. These results combined with those of the control samples from the first treatability test might indicate that the presence of only a small amount of water in the soil has the most significant impact on the extraction of PCBs from soil. This effect may also be amplified by the presence of highly alkaline conditions in the soil.

The results from these studies highlight the importance of verifying that proper sample processing procedures are adhered to when assessing the efficacy of treatment processes for PCB-contaminated soil. It appears to be rather easy to generate erroneous results due to poor recovery of PCBs when the samples are not neutralized and/ or effectively dried prior to extraction. 


\section{References}

Agency for Toxic Substances and Disease Registry (ATSDR). 2000. Toxicological profile for polychlorinated biphenyls (PCBs). Atlanta, GA: U.S. Department of Health and Human Services, Public Health Service.

Britto, B., M. Patel, and M. Spangberg. 2010. Full-scale alkaline hydrolysis of TNT and DNT in soil. Presented at The Seventh International Conference for Remediation of Chlorinated and Recalcitrant Compounds. 24-27 May, Monterey, CA. http://www.tetratech.com/tetratech/papers-and-articles/view-category.html.

Brunelle, D. J., A. K. Mendiratta, and D. A.Singleton. 1985. Reaction/ removal of polychlorinated biphenyls from transformer oil: Treatment of contaminated oil with poly(ethylene glycol)/KOH. Environ. Sci.Technol. 19(8), 740-746.

Brunelle, D. J., and D. A. Singleton. 1985. Chemical reaction of polychlorinated biphenyls on soils with poly(ethylene glycol)/ $\mathrm{KOH}$. Chemosphere 14(2), 173-181.

Cassidy, D. P. 2010. Degradation vs. Entrapment of PAHs and PCBs During Slurry Treatment with Hydrated Lime and Lime-Activated Persulfate. Report prepared for FMC Inc.

Dàvila, B., K. W. Whitford, and E. S. Saylor. 1993. Technology alternatives for the remediation of PCB-contaminated soil and sediment. EPA/540/S-93/506, Cincinnati, OH: U.S. Environmental Protection Agency, Risk Reduction Engineering Laboratory.

Ehsan S., S. O. Prasher, and W. D. Marshall. 2007. Simultaneous mobilization of heavy metals and polychlorinated biphenyl (PCB) compounds from soil with cyclodextrin and EDTA in admixture. Chemosphere 68, 150-158.

Einhaus, R. L., I. Honarkhah, and P. Erickson. 1991. Fate of polychlorinated biphenyls (PCBs) in soil following stabilization with quicklime. U.S. EPA 600/2-91/ 052. Cincinnati, OH: Risk Reduction Engineering Laboatory.

Hong A. P. K., S. Nakra, J . C. M. Kao, and D. F. Hayes 2008. Pressure-assisted ozonation of PCB and PAH contaminated sediments. Chemosphere 72, 1757-1764.

Hutzinger, O., S. Safe, and V. Zitko. 1974. The chemistry of PCB's Cleveland, OH: CRC Press.

Kolthoff, I. M., and I. K. Miller. 1951. The chemistry of persulfate. I. The kinetics and mechanisms of the decomposition of the persulfate ion in aqueous medium. J . Am. Chem. Soc. 73(7), 3055-3059.

Manchak, F. (1978). Methods of transforming sludge into ecologically acceptable solid material. U.S. Patent No. 4,079,003. 
McElroy, R. 2005. On-site PCB soil remediation - sonic's technology demonstration. Presented at The 2005 Association of the Environmental Health of Soils West Coast Conference on Contaminated Soils, Sediments and Water. San Diego, CA. Available on line at: http://sesi.xplorex.com/sites/sesi/files/ OnSite_PCB_Soil_Remediation_Sonics_Technology_Demonstration.pdf

Medina, V. F., S. A. Waisner, A. B. Morrow, C. C. Nestler, and M. J ones. 2007. Evaluation of lime and persulfate treatment for mixed contaminant soil from Plum Brook Ordnance Works (Sandusky, OH). ERDC/ EL TR-07-19. Vicksburg, MS: U.S. Army Engineer Research and Development Center.

Osgerby, I. T., H. Y. Takemoto, R. Watts, and A. Beaudin. 2002. Remediation of PCBcontaminated, predominantly aragonite soils in Saipan using modified Fenton's chemistry. In Proceedings of Battelle Bioremediation Conference.

Payne, J ., F. Boelsing, A. Habekost, G. Hirschfeld, and V. Birke. 1991. Complete ambienttemperature dehalogenation of PCBs in contaminated soil using hydrophobic lime and other reagents EPRI PCB Seminar, Oct. 8-11, Baltimore, MD.

Robinson K. G., M. M. Ghosh, and Z. Shi. 1996. Mineralization enhancement of nonaqueous phase and soil-bound PCB using biosurfactant. Water Science and Technology 34, 303-309.

Sedlak, D. L., K. E. Dean, D. E. Armstrong, and A. W. Andren. 1991. Interaction of quicklime with polychlorobiphenyl-contaminated solids. Environ.Sci.Technol. 25(11), 1936-1940.

Seok, J ., J . Soek, and K.-Y. Hwang. 2005. Thermo-chemical destruction of polychlorinated biphenyls (PCBs) in waste insulating oil J . Hazard. Mats. B124, 133-138.

Soundararajan, R. 1991. Appendix A. Final report on the "disappearing PCBs" project. Fate of polychlorinated biphenyls (PCBs) in soil following stabilization with quicklime. EPA/600/ 2-91/ 052. Washington, DC.

Svab, M., M. Kubal, M. Mnllerova, and R. Raschman. 2009. Soil flushing by surfactant solution: Pilot-scale demonstration of complete technology. J ournal of Hazardous Materials 163, 410-417.

Taniguchi S., A. Murakami , M. Hosomi, A. Miyamura, and R. Uchida. 2003. Chemical decontamination of PCB-contaminated soil. Chemosphere 34, 1631-1637.

Thyagarajan, B. S. 1983. Process for treatment of fluids contaminated with polychlorinated biphenyls. U.S. Patent number 4,612,404.

United States Environmental Protection Agency (EPA). 1992. AOSTRA-SoilTech Anaerobic Thermal Processor: Wide Beach Development Site. EPA/540/MR92/ 008. SITE (Superfund Innovative Technology Evaluation).

Varanasi P., A. Fullanaand, and S. Sidhu. 2007. Remediation of PCB contaminated soils using iron nano-particles. Chemosphere 66, 1031-1038.

Waisner, S., V. F. Medina, A. G. Morrow, and C. C. Nestler. 2008. Evaluation of chemical treatments for a mixed contaminant soil. J . Environ. Eng. 134(9), 743-749. 
Weber, R., T. Takasuga, K. Nagai, H. Shiraishi, T. Sakurai, T. Matuda, and M. Hiraoka. 2002. Dechlorination and destruction of PCDD, PCDF and PCB on selected fly ash from municipal waste incineration. Chemosphere, 46, 1255-1262. 


\section{Appendix A: Cost Comparison of PCB- contaminated Soil Disposal at a Hazardous Waste Landfill Versus On-site Treatment, Assuming a Remote Alaskan Site. (Prepared with assistance from Neil Folcik, Ron Broyles, \& Scott Kendall of Alaska District)}

Cost Comparison for Off-Site Disposal versus On-Site Treatment for PCBcontaminated soil from a remote Alaska District site such as Tanaga Island. Assumed quantity of contaminated soil: 10 tons.

1. Off-Site Disposal $=\$ 515,600$

Mobilization/ Demobilization - Anchorage to Tanaga

- Includes small barge/ tug to transport equipment, supplies, and waste streams between Anchorage and Tanaga Island. Barge will stop in Adak, Alaska to pick up crew

- Excavator, morooka, loader, and waste containers will be on barge.

- Field crew includes 4 people (operator, superintendent, QC, and laborer)

- 18 days required for $\mathrm{mob} / \mathrm{demob}$

o 18 days barge (includes equipment standby time) $=\$ 424,000$

- $\mathrm{Mob} /$ demob field crew to Adak (includes airfare and travel time) $=$ $\$ 9200$

- Mob/ demob field crew to Tanaga (includes travel time) $=\$ 4000$

o Total $=\$ 437,200$

Field Work

- Contaminated soil is located in an area that is within 1 mile of the beach. The contaminated soil is accessible without significant site access improvements.

- A remote camp is not required. Due to the small scale of the project and its short duration, the crew will use the barge quarters. 
- Assume 3 days to unload barge, excavate soil, load super sacks, backfill excavation, and load barge.

o Labor $=\$ 14,400$

o Waste container rental, field crew food, fuel, confirmation sampling, etc. $=\$ 6,000$

- Barge standby $=\$ 48,000$

o Total $=\$ 68,400$

Contaminated soil transportation/ disposal - Anchorage to Oregon

- Includes transporting the soil to Oregon for disposal.

o Transport/ dispose of soil (based on quote obtained by Scott Kendall $)=\$ 10,000$

2. Onsite Treatment $=\sim \$ 492,200$

Mobilization/ Demobilization - Anchorage to Tanaga

Equipment and crew are shipped to Adak, Alaska on Alaska Airlines and/ or scheduled barge.

Helicopter will fly (pilots only) from Anchorage, Alaska to Adak.

One helicopter trip to deliver a mini-excavator / loader (e.g, Bobcat MT52 Mini loader, $2580 \mathrm{lbs}$ ), and soil amendments; 2nd helicopter to transport field and camp supplies, third trip to transport crew between Adak and Anchorage. Mini-loader would be equipped with attachments for scarifying soil to aid with excavation. PCB-contaminated soil is assumed to be present near the surface, due in part to the strong affinity for soils and low solubility. Roto-tiller would also be delivered to site for mixing.

Field crew size 4 people

- helicopter rental ( $\$ 12,100 /$ day) (Assume 2 weather days and 4 flight days) $=\$ 72,600$

- Helicopter fuel staging between Dutch Harbor and Adak $=\$ 25,000$

- $\mathrm{mob} / \mathrm{demob}$ of field crew (includes airfare, labor, and per diem $=$ $\$ 15,000$ 
- temporary camp $=\$ 12,000$

- Shipping equipment, supplies, and remote camp to/from Adak = $\$ 16,000$

- Total $=\$ 140,600$

o Mini-excavator / loader/mixer and soil amendments will be delivered via helicopter.

o A temporary camp is required.

- 4 days required for $\mathrm{mob} / \mathrm{demob}$

o Field crew includes 4 people (operator, engineer, and 2 laborers)

Field Work

- Contaminated soil is located in an area that is within 1 mile of the beach. The contaminated soil is accessible without significant site access improvements.

- Assume 7 days to unload equipment, excavate soil, build stockpile, treat soil, allow reaction to occur, test soil. Mini-excavator is left on site (will not be retrieved until backfilling is complete). Due to the short length of the field effort, the 4-6 days required for mob/ demob, and health and safety reasons the helicopter will remain onsite for the duration of the field work. Labor $=\$ 25,200$

o Stockpile material, field crew food, fuel, confirmation sampling, etc. $=\$ 8000$

o Soil treatment supplies $=\$ 10,000$

o Helicopter rental $=84,700$

o Total $=\$ 127,900$

Mobilization/ Demobilization - Backfill

Equipment and crew are shipped to Adak Alaska on Alaska Airlines and/ or scheduled barge. Helicopter will be used to transport crew from Adak to Tanaga.

Field crew size: 4 people

4 days for $\mathrm{mob} / \mathrm{demob}$

- helicopter rental (includes fuel) $=\$ 48,400$ 
- $\mathrm{mob} /$ demob of field crew $=\$ 12,000$

- Total $=\$ 60,400$

Field Work - Backfill

3 days to complete backfill activities

The excavation will be backfilled and stockpile will be decommissioned by hand. Helicopter would be required for retrieving mini-excavator.

- helicopter rental $=\$ 36,300$

- labor of field crew $=\$ 9,000$

- field crew food, remote camp, etc. $=\$ 4,000$

- Total $=\$ 49,300$

Contingency Factor

Assume $\sim 30 \%$ contingency factor to account for uncertainties (e.g., transportation delays due to adverse weather, potential need for an additional helicopter round-trip, reaction time need for treatment process, etc).

- Contingency factor $=\$ 114,000$ 


\section{Appendix B: Particle Size Distribution of Umiat, AK Soil}

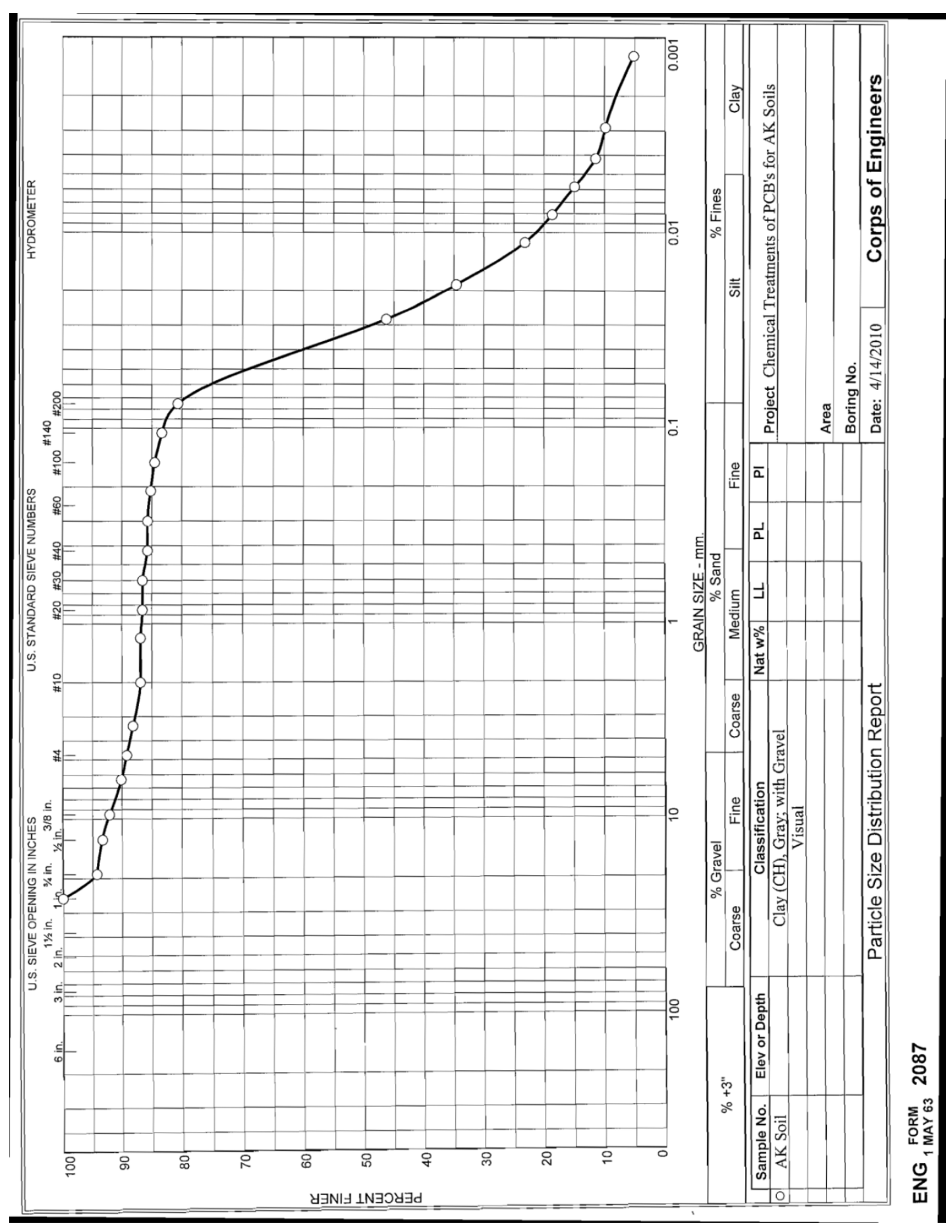




\title{
Appendix C: Material Safety Data Sheets for Tween 80
}

\author{
Material Safety Data Sheet \\ Tween $\AA 80$
}

ACC\# 40200

\section{Section 1 - Chemical Product and Company Identification}

MSDS Name: Tween $® 80$

Catalog Numbers: AC278630000, AC278630010, AC278630050, AC278632500, BP338-500,

NC9011213, NC9252526, T164-500, T164500LC

Synonyms: Polyoxyethylene(20)sorbitan monooleate.

Company Identification:

Fisher Scientific

1 Reagent Lane

Fair Lawn, NJ 07410

For information, call: 201-796-7100

Emergency Number: 201-796-7100

For CHEMTREC assistance, call: 800-424-9300

For International CHEMTREC assistance, call: 703-527-3887

Section 2 - Composition, Information on Ingredients
\begin{tabular}{|c|r|c|c|}
\hline CAS\# & Chemical Name & Percent & EINECS/ELINCS \\
\hline $9005-65-6$ & Tween $(8) 80$ & 100 & unlisted \\
\hline
\end{tabular}

\section{Section 3 - Hazards Identification}

\section{EMERGENCY OVERVIEW}

Appearance: clear yellow to amber viscous liquid.

Caution! May cause eye, skin, and respiratory tract irritation. The toxicological properties of this material have not been fully investigated.

Target Organs: None known.

Potential Health Effects

Eye: May cause eye irritation.

Skin: May cause skin irritation. May be harmful if absorbed through the skin.

Ingestion: May cause irritation of the digestive tract. May be harmful if swallowed.

Inhalation: May cause respiratory tract irritation. May be harmful if inhaled.

Chronic: No information found.

\section{Section 4 - First Aid Measures}

Eyes: Immediately flush eyes with plenty of water for at least 15 minutes, occasionally lifting the upper and lower eyelids. If irritation develo ps, get medical aid.

Skin: Immediately flush skin with plenty of water for at least 15 minutes while removing 
contaminated clothing and shoes. Get medical aid if irritation develops or persists.

Ingestion: Do not induce vomiting. Get medical aid if irritation or symptoms occur.

Inhalation: Remove from exposure and move to fresh air immediately. If not breathing, give artificial respiration. If breathing is difficult, give oxygen. Get medical aid if cough or other symptoms appear.

Notes to Physician: Treat symptomatically and supportively.

\section{Section 5 - Fire Fighting Measures}

General Information: As in any fire, wear a self-contained breathing apparatus in pressuredemand, MSHA/NIOSH (approved or equivalent), and full protective gear.

Extinguishing Media: Use water spray, dry chemical, carbon dioxide, or appropriate foam.

Flash Point: > $110 \mathrm{deg} \mathrm{C}(>230.00 \mathrm{deg}$ F)

Autoignition Temperature: Not applicable.

Explosion Limits, Lower: Not available.

Upper: Not available.

NFPA Rating: (estimated) Health: 1; Flammability: 1; Instability: 0

\section{Section 6 - Accidental Release Measures}

General Information: Use proper personal protective equipment as indicated in Section 8. Spills/Leaks: Absorb spill with inert material (e.g. vermiculite, sand or earth), then place in suitable container. Provide ventilation. Do not let this chemical enter the environment.

\section{Section 7 - Handling and Storage}

Handling: Avoid contact with eyes, skin, and clothing. Avoid ingestion and inhalation. Use with adequate ventilation.

Storage: Store in a cool, dry place. Store in a tightly closed container. Store at around $20^{\circ} \mathrm{C}$.

\section{Section 8 - Exposure Controls, Personal Protection}

Engineering Controls: Facilities storing or utilizing this material should be equipped with an eyewash facility and a safety shower. Use adequate ventilation to keep airborne concentrations low.

Exposure Limits Chemical Name Tween(B) 80

\begin{tabular}{|c|c|c|}
\hline ACGIH & NIOSH & OSHA - Final PELS \\
\hline none listed & none listed & none listed \\
\hline
\end{tabular}

OSHA Vacated PELs: Tween $®$ 80: No OSHA Vacated PELs are listed for this chemical. Personal Protective Equipment

Eyes: Wear appropriate protective eyeglasses or chemical safety goggles as described by OSHA's eye and face protection regulations in 29 CFR 1910.133 or European Standard EN166.

Skin: Wear appropriate protective gloves to prevent skin exposure.

Clothing: Wear appropriate protective clothing to prevent skin exposure. 
Respirators: Follow the OSHA respirator regulations found in 29 CFR 1910.134 or European Standard EN 149. Use a NIOSH/MSHA or European Standard EN 149 approved respirator if exposure limits are exceeded or if irritation or other symptoms are experienced.

\section{Section 9 - Physical and Chemical Properties}

Physical State: Viscous liquid

Appearance: clear yellow to amber

Odor: Not available.

pH: 6 (10\% aq.sol.)

Vapor Pressure: < $1 \mathrm{hPa} @ 20 \mathrm{deg} \mathrm{C}$

Vapor Density: $>1.0$

Evaporation Rate: $>1$ (ether=1)

Viscosity: 400 mPas @ 25 deg C

Boiling Point: $100 \mathrm{deg} \mathrm{C}$

Freezing/Melting Point:Not available.

Decomposition Temperature:Not available.

Solubility: $100 \mathrm{~g} / \mathrm{L}$

Specific Gravity/Density: 1.080

Molecular Formula:Not applicable.

Molecular Weight: Not available.

\section{Section 10 - Stability and Reactivity}

Chemical Stability: Stable under normal temperatures and pressures.

Conditions to Avoid: Incompatible materials, excess heat.

Incompatibilities with Other Materials: Strong oxidizing agents, bases, heavy metal salts.

Hazardous Decomposition Products: Carbon monoxide, carbon dioxide.

Hazardous Polymerization: Has not been reported.

\section{Section 11 - Toxicological Information}

\section{RTECS\#:}

CAS\# 9005-65-6: WG2932500

LD50/LC50:

CAS\# 9005-65-6:

Draize test, rabbit, eye: $150 \mathrm{mg}$ Mild;

Oral, mouse: $\mathrm{LD} 50=25 \mathrm{gm} / \mathrm{kg}$;

Oral, rat: $\mathrm{LD} 50=34500 \mathrm{uL} / \mathrm{kg}$;

Carcinogenicity:

CAS\# 9005-65-6: Not listed by ACGIH, IARC, NTP, or CA Prop 65.

Epidemiology: Tumorigenic effects have been reported in experimental animals.

Teratogenicity: Teratogenic effects have occurred in experimental animals.

Reproductive Effects: Adverse reproductive effects have occurred in experimental animals.

Mutagenicity: No information available. 
Neurotoxicity: No information available.

Other Studies:

\section{Section 12 - Ecological Information}

Ecotoxicity: No data available. No information available.

Environmental: No information found.

Physical: No information found.

Other: Do not empty into drains.

\section{Section 13 - Disposal Considerations}

Chemical waste generators must determine whether a discarded chemical is classified as a hazardous waste. US EPA guidelines for the classification determination are listed in 40 CFR Parts 261.3. Additionally, waste generators must consult state and local hazardous waste regulations to ensure complete and accurate classification.

RCRA P-Series: None listed.

RCRA U-Series: None listed.

\section{Section 14 - Transport Information}

\begin{tabular}{|c|c|c|}
\hline \multicolumn{1}{|c|}{ US DOT } & Canada TDG \\
\hline Shipping Name: & Not regulated. & Not regulated. \\
\hline Hazard Class: & & \\
\hline UN Number: & & \\
\hline Packing Group: & & \\
\hline
\end{tabular}

\section{Section 15 - Regulatory Information}

\section{US FEDERAL}

TSCA

CAS\# 9005-65-6 is listed on the TSCA inventory.

Health \& Safety Reporting List

None of the chemicals are on the Health \& Safety Reporting List.

Chemical Test Rules

None of the chemicals in this product are under a Chemical Test Rule.

Section 12b

None of the chemicals are listed under TSCA Section 12b.

TSCA Significant New Use Rule

None of the chemicals in this material have a SNUR under TSCA.

CERCLA Hazardous Substances and corresponding RQs

None of the chemicals in this material have an RQ.

SARA Section 302 Extremely Hazardous Substances

None of the chemicals in this product have a TPQ.

Section $313 \quad$ No chemicals are reportable under Section 313.

Clean Air Act: 
This material does not contain any hazardous air pollutants.

This material does not contain any Class 1 Ozone depletors.

This material does not contain any Class 2 Ozone depletors.

Clean Water Act:

None of the chemicals in this product are listed as Hazardous Substances under the CWA.

None of the chemicals in this product are listed as Priority Pollutants under the CWA.

None of the chemicals in this product are listed as Toxic Pollutants under the CWA.

OSHA:

None of the chemicals in this product are considered highly hazardous by OSHA.

STATE

CAS\# 9005-65-6 is not present on state lists from CA, PA, MN, MA, FL, or NJ.

\section{California Prop 65}

California No Significant Risk Level: None of the chemicals in this product are listed.

\section{European/International Regulations}

European Labeling in Accordance with EC Directives

Hazard Symbols:

Not available.

\section{Risk Phrases:}

\section{Safety Phrases:}

S 24/25 Avoid contact with skin and eyes.

WGK (Water Danger/Protection)

CAS\# 9005-65-6: 1

Canada - DSL/NDSL

CAS\# 9005-65-6 is listed on Canada's DSL List.

Canada - WHMIS

This product has a WHMIS classification of D2B.

This product has been classified in accordance with the hazard criteria of the Controlled Products Regulations and the MSDS contains all of the information required by those regulations.

\section{Canadian Ingredient Disclosure List}

\section{Section 16 - Additional Information}

MSDS Creation Date: 7/15/1999

Revision \#8 Date: 11/29/2007

The information above is believed to be accurate and represents the best information currently available to us. However, we make no warranty of merchantability or any other warranty, express or implied, with respect to such information, and we assume no liability resulting from its use. Users should make their own investigations to determine the suitability of the information for their particular purposes. In no event shall Fisher be liable for any claims, losses, or damages of any third party or for lost profits or any special, indirect, incidental, consequential or exemplary damages, howsoever arising, even if Fisher has been advised of the possibility of such damages. 


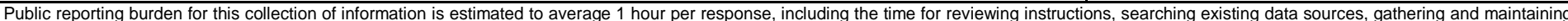

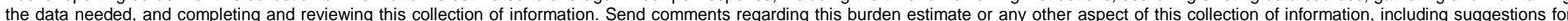

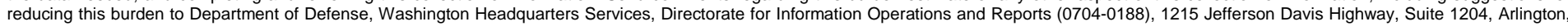

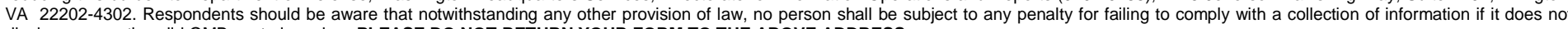
display a currently valid OMB control number. PLEASE DO NOT RETURN YOUR FORM TO THE ABOVE ADDRESS.
1. REPORT DATE (DD-MM-YYYY) 2. REPORT TYPE
April 2011
Final report

\section{TITLE AND SUBTITLE}

Chemical Degradation of PCBs in Alaskan Soils

3. DATES COVERED (From - To)

5a. CONTRACT NUMBER

5b. GRANT NUMBER

5c. PROGRAM ELEMENT NUMBER

\section{AUTHOR(S)}

Scott A. Waisner, P.E., Agnes B. Morrow, Catherine C. Nestler, Charles Coyle, P.E., and

Victor F. Medina, Ph.D., P.E.

5d. PROJECT NUMBER

5e. TASK NUMBER

5f. WORK UNIT NUMBER

\section{PERFORMING ORGANIZATION NAME(S) AND ADDRESS(ES)}

8. PERFORMING ORGANIZATION REPORT NUMBER

U.S. Army Engineer Research and Development Center

Environmental Laboratory

ERDC/EL TR-11-3

3909 Halls Ferry Road

Vicksburg, MS 39180-6199

9. SPONSORING I MONITORING AGENCY NAME(S) AND ADDRESS(ES)

10. SPONSOR/MONITOR'S ACRONYM(S)

Headquarters, U.S. Army Corps of Engineers

Washington, DC 20314-1000

11. SPONSOR/MONITOR'S REPORT NUMBER(S)

\section{DISTRIBUTION / AVAILABILITY STATEMENT}

Approved for public release; distribution is unlimited.

\section{SUPPLEMENTARY NOTES}

\section{ABSTRACT}

Previous work suggested that the addition of lime could promote the removal of polychlorinated biphenyls (PCBs), presumably by alkaline hydrolysis reactions. A study was conducted to determine if a modified process (substituting sodium hydroxide (NaOH) for lime) could be used to treat PCB-contaminated soils in remote areas of Alaska. Experiments in which soils were reacted with $2 \% \mathrm{NaOH}$ and a $\mathrm{NaOH} /$ zero valent iron mixture resulted in an approximate 20 to 30\% reduction of Aroclor concentration compared to the controls. Tests applying Tween 80 at 15\% (w/w) with $\mathrm{NaOH}$ at $2 \%(\mathrm{w} / \mathrm{w})$ indicated that the Tween 80 increased PCB release from soil, but no significant PCB degradation was found. An experiment was then conducted to investigate the use of persulfate to treat PCBs in solution. Heat-activated $\left(50^{\circ} \mathrm{C}\right)$ sodium persulfate $\left(\mathrm{Na}_{2} \mathrm{~S}_{2} \mathrm{O}_{8}\right)$ removed $>90 \%$ of the PCBs (Aroclor 1254), but lime-activated persulfate was ineffective. A final study was conducted to investigate the effect of hydroxide and lime on PCB extraction and the effect of $\mathrm{pH}$ neutralization. The study was inconclusive, as it did not appear any net losses were demonstrated. The overall study indicated that alkaline hydrolysis does not appear to be effective for the treatment of the subject Alaska soils. Some promise might be found for heatactivated persulfate treatment, although the more easily applied lime activation was not effective.

15. SUBJECT TERMS

Alkaline hydrolysis

Formerly used defense sites (FUDS)

16. SECURITY CLASSIFICATION OF:

\begin{tabular}{|l|l|l|}
\hline a. REPORT & b. ABSTRACT & c. THIS PAGE \\
UNCLASSIFIED & UNCLASSIFIED & UNCLASSIFIED \\
\hline
\end{tabular}

PCB degradation PCB removal

17. LIMITATION
OF ABSTRACT
UNLIMITED

Polychlorinated biphenyis (PCBs)

\begin{tabular}{c|l}
$\begin{array}{c}\text { 18. NUMBER } \\
\text { OF PAGES }\end{array}$ & $\begin{array}{l}\text { 19a. NAME OF RESPONSIBLE } \\
\text { PERSON }\end{array}$ \\
\cline { 2 - 2 } 47 & $\begin{array}{l}\text { 19b. TELEPHONE NUMBER (include } \\
\text { area code) }\end{array}$ \\
\hline
\end{tabular}




\section{PERFORMING ORGANIZATION NAME(S) AND ADDRESS(ES) (concluded)}

U.S. Army Corps of Engineers

Environmental and Munitions Center of Expertise 1616 Capitol Ave., Suite 9200

Omaha, NE 68102-9200

Applied Research Associates, Inc., Southern Division 119 Monument Place

Vicksburg, MS 39180 